\title{
Disentangling the link between supplemental feeding, population density, and the prevalence of pathogens in urban stray cats
}

\author{
Jusun Hwang ${ }^{1,2}$, Nicole L Gottdenker ${ }^{2}$, Dae-Hyun Oh ${ }^{1}$, Ho-Woo Nam ${ }^{3}$, Hang Lee ${ }^{1}$, Myung-Sun Chun Corresp. 1 \\ ${ }^{1}$ College of Veterinary Medicine, Seoul National University, Seoul, South Korea \\ 2 Department of Veterinary Pathology, University of Georgia, Athens, Georgia, United States \\ 3 Parasitic Disease Research Institute, College of Medicine, Catholic University of Korea, Seoul, South Korea \\ Corresponding Author: Myung-Sun Chun \\ Email address: jdchun@snu.ac.kr
}

Background Supplemental feeding of free-roaming animals, including wildlife and feral or stray animals, is well known to have a substantial impact on various aspects of animal ecology including habitat use, activity patterns, and host-pathogen interactions. Among them, an increased population density of animals receiving supplemental food raises concerns regarding the transmission of pathogens in these host populations. The primary aim of this study was to investigate how supplemental feeding is associated with host population density and prevalence of pathogens with different transmission modes in urban stray cats. We hypothesized that supplemental feeding would be positively associated with host population density and the prevalence of pathogens with density-dependent transmission modes compared with pathogens with transmission modes that are considered relatively density-independent. Methods This study was conducted in six districts in Seoul, Republic of Korea which were selected based on different degrees of supplemental feeding and cat caretaker activity (CCA). The population density of stray cats was estimated by mark-recapture surveys. Stray cat blood samples $(N=302)$ were collected from stray cats by local animal hospitals from each district performing the trap-neuter-release (TNR) which tested for 8 pathogens with different transmission modes (feline immunodeficiency virus, feline leukemia virus, feline panleukopenia virus, feline calicivirus, feline herpesvirus-1, Bartonella henselae, hemoplasma and Toxoplasma gondii) with molecular or serological assays. Associations between the prevalence of each pathogen and population density, CCA, and sex of cats were statistically analyzed. Results In contrast to initial predictions, the cat population density was generally higher in low CCA districts. The prevalence of feline leukemia virus, which is transmitted through direct contact, was significantly higher in areas with a high CCA, conforming to our hypothesis. On the other hand, the prevalence of feline parvovirus, which can be spread by environmental transmission, was higher in low CCA districts. The remaining six pathogens did not show any association with the CCA; however, they had a unique association with the population density or the sex of the stray cats. Discussion Our findings suggest that in addition to influencing the population density, supplemental feeding may affect the prevalence of pathogens in urban animals by mechanisms such as increased aggregation and/or altered foraging strategies, with different consequences depending on the transmission mode of each pathogen. 
1 Disentangling the link between supplemental feeding, population density, and prevalence of

2 pathogens in urban stray cats

3

4 Short title: Supplemental feeding in urban stray cats

5

6 Jusun Hwang ${ }^{1,2 \# a}$, Nicole Gottdenker ${ }^{1}$, Dae-Hyun $\mathrm{Oh}^{2}$, Ho-Woo Nam ${ }^{3}$, Hang Lee ${ }^{2}$, Myung-Sun

7 Chun $^{2 *}$,

8 1. Department of Veterinary Pathology, College of Veterinary Medicine, University of Georgia,

9 Athens, Georgia, USA

10 2. College of Veterinary Medicine, Seoul National University, Seoul, Republic of Korea

11 3. Parasitic Disease Research Institute, College of Medicine, Catholic University, Seoul, Republic

12 of Korea

13

14

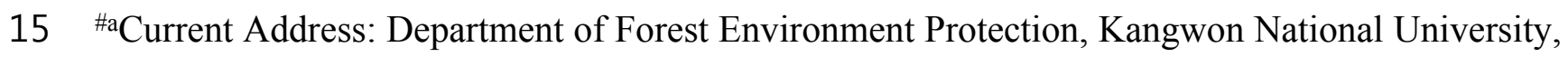

16 Chuncheon, Korea

17

18 *Corresponding author

19 Myung-sun Chun

20 E-mail:

21 jdchun@snu.ac.kr

22

\section{Abstract}




\section{Background}

25 Supplemental feeding of free-roaming animals, including wildlife and feral or stray animals, is 26 well known to have a substantial impact on various aspects of animal ecology including habitat 27 use, activity patterns, and host-pathogen interactions. Among them, an increased population 28 density of animals receiving supplemental food raises concerns regarding the transmission of 29 pathogens in these host populations. The primary aim of this study was to investigate how 30 supplemental feeding is associated with host population density and prevalence of pathogens with 31 different transmission modes in urban stray cats. We hypothesized that supplemental feeding 32 would be positively associated with host population density and the prevalence of pathogens with 33 density-dependent transmission modes compared with pathogens with transmission modes that are 34 considered relatively density-independent.

\section{Methods}

36 This study was conducted in six districts in Seoul, Republic of Korea which were selected based 37 on different degrees of supplemental feeding and cat caretaker activity (CCA). The population 38 density of stray cats was estimated by mark-recapture surveys. Stray cat blood samples $(\mathrm{N}=302)$ 39 were collected from stray cats by local animal hospitals from each district performing the trapneuter-release (TNR) which tested for 8 pathogens with different transmission modes (feline

41 immunodeficiency virus, feline leukemia virus, feline panleukopenia virus, feline calicivirus, 42 feline herpesvirus-1, Bartonella henselae, hemoplasma and Toxoplasma gondii) with molecular or 43 serological assays. Associations between the prevalence of each pathogen and population density, 44 CCA, and sex of cats were statistically analyzed.

\section{Results}


46 In contrast to initial predictions, the cat population density was generally higher in low CCA

47 districts. The prevalence of feline leukemia virus, which is transmitted through direct contact, was

48 significantly higher in areas with a high CCA, conforming to our hypothesis. On the other hand,

49 the prevalence of feline parvovirus, which can be spread by environmental transmission, was

50 higher in low CCA districts. The remaining six pathogens did not show any association with the

51 CCA; however, they had a unique association with the population density or the sex of the stray

52 cats.

\section{Discussion}

54 Our findings suggest that in addition to influencing the population density, supplemental feeding 55 may affect the prevalence of pathogens in urban animals by mechanisms such as increased 56 aggregation and/or altered foraging strategies, with different consequences depending on the 57 transmission mode of each pathogen.

\section{Introduction}

Supplemental feeding of free-ranging animals is a common practice worldwide that occurs

61 through multiple direct (e.g., feeding for conservation management and backyard bird feeders) or

62 indirect (e.g., urban trash cans and pet's food outdoors) routes (Oro et al., 2013; Becker, Streicker 63 \& Altizer, 2015; Murray et al., 2016). However, an increasing number of studies have raised 64 concerns regarding the impact of anthropogenic food supplementation on various aspects of animal 65 ecology, ranging from individual phenotypic traits (e.g., body size and immunocompetence), 66 population dynamics (e.g. survival rate, breeding rate and population density), to pathogen host 67 community composition (Robb et al., 2008; Rodriguez-Hidalgo et al., 2010; Jessop et al., 2012; 68 Galbraith et al., 2015). For instance, increased body mass, population density, and reproduction 
69 rates were observed in red deer (Cervus elaphus) that were provided with artificial food sources in

70 effort to maintain their population size as a game species (Vicente et al., 2007; Rodriguez-

71 Hidalgo et al., 2010). These accumulated changes in individual biology and population dynamics

72 are suspected to have further and unexpected consequences on disease transmission because the

73 dependence of animals on supplemented food can ultimately alter their exposure and/or

74 susceptibility to pathogens. Among diverse mechanisms linking supplemental feeding and altered

75 host-pathogen interactions, a heightened population density (increase in general abundance of

76 animals in a certain area) and crowding (spatiotemporal aggregation of animals) of host individuals

77 has been frequently discussed for several reasons. For instance 1) increased stress of the animals

78 as a result of crowding may lead to negative influences on the immune function of animals and

79 their susceptibility of pathogen infection (Semeniuk CAD \& Rothley KD, 2008; Forristal et al.,

80 2012), while 2) increased frequency of close contact between infectious and susceptible host

81 individuals around the food source may mechanically accelerate the transmission of pathogens.

82 This has been particularly well documented in avian species regarding backyard bird feeders,

83 where the crowding of birds contributes to the spread of mycoplasma conjunctivitis, caused by

84 Mycoplasma gallisepticum (Adelman et al., 2015; Moyers, 2017).

85 The influence of supplemental feeding on host-pathogen interactions as a result of

86 increased host population density can further be complicated because the response of a pathogen

87 to host density may vary based on its unique transmission mode. Theoretically, pathogen

88 transmission dynamics are commonly categorized based on different assumptions about the

89 dependence of pathogen transmission on population density of host populations. Pathogens

90 transmission through contact that increases proportionately with population density, is regarded as

91 "density-dependent transmission", whereas when pathogen transmission is driven by the 
92 "frequency of infected contacts", independent of host density, it is identified as "frequency93 dependent transmission". For pathogen groups adopting density-dependent transmission, its 94 transmission is facilitated as host population density increases and the chances of individuals 95 having contacts in close proximity becomes frequent, , as with Brucella abortus in ungulates. 96 (Dobson \& Meagher, 1996). However, pathogens with frequency-dependent transmission modes, 97 such as vector-borne and sexually or trophically-transmitted pathogens, often depend on specific 98 behaviors of the infectious vectors or host individuals, such as aggressive behavior during the 99 breeding season or exposure to hematophagous arthropods, which enables the transmission of the 100 pathogens, rather than population density or physical contact in proximity among host individuals 101 (Thrall, Antonovics \& Hall, 1993). In relation to supplemental feeding, increased host aggregation 102 in response to a spatiotemporally stable food source may increase the transmission of directly 103 transmitted pathogens as observed in the increased prevalence of endoparasites in raccoons 104 (Procyon lotor) with altered contact rates (Wright \& Gompper, 2005). However, it is possible that 105 such a pattern may not apply to other pathogens as observed in the cases of decreased prevalence 106 of echinococcosis in urban red foxes (Vulpes vulpes) compared to those in rural area, potentially 107 due to their reduced predation on intermediate hosts in urban habitats (Fischer et al., 2005). 108 However, to date, few studies have simultaneously evaluated the linkages between supplemental 109 feeding and the prevalence of pathogens with differing transmission modes (Miller et al., 2003; 110 Vicente et al., 2007; Brennan et al., 2014).

111 Modifications of host-pathogen interactions due to supplemental feeding may also apply 112 to other free-roaming animals. Among them, domestic cats (Felis catus) are one of the species that 113 have managed to prosper in a wide range of habitats, including well developed cities (Bateman \& 114 Fleming, 2012). Urban free-roaming cats can benefit from surplus food sources provided by urban 
115 residents. These residents who regularly or sporadically provide a supplemental food source for

116 free-roaming cats are commonly referred to as cat caretakers (Centonze \& Levy, 2002; Finkler,

117 Hatna \& Terkel, 2011b; Peterson et al., 2012). There are many ecological and sociological issues

118 centered around free-roaming cats, as the availability of predictable food sources and a stable

119 energy intake are known to increase the overall abundance of supplemented animals (López-Bao

120 et al., 2010; Rickett et al., 2013; Plummer et al., 2013). Among them, the epidemiological role of

121 urban free-roaming cats regarding public health and the health of other domestic and wild animals

122 is a subject of concern (Lepczyk, Lohr \& Duffy, 2015). The most well-known zoonotic pathogens

123 and diseases infecting cats include rabies, Toxoplasma gondii, and various arthropod-borne

124 pathogens such as Bartonella henselae and Rickettsia species (Gerhold \& Jessup, 2013; Spada et 125 al., 2014).

126

The aim of this study was to examine how human food provisioning, host population

127 density, and pathogen prevalence are associated in urban stray cats while asking how these

128 relationships vary with the transmission modes of each pathogen. Here, we defined the group of

129 unowned and free-roaming cats In a city as urban stray cats. We investigated the prevalence of 130 eight feline pathogens, feline calicivirus (FCV), feline herpesvirus-1 (FHV-1), feline leukemia 131 virus (FeLV), feline immunodeficiency virus (FIV), feline hemoplasma, Bartonella henselae, 132 feline parvovirus (FPV) and Toxoplasma gondii. Each of these pathogens has a different 133 transmission mode, falling somewhere along the continuum of density-dependent and frequency134 dependent transmission (Table 1) (Fenton et al., 2002; Begon et al., 2002; Greer, Briggs \& Collins, 135 2008). FCV, FHV-1 and FeLV are pathogens with density-dependent transmission modes because 136 its transmission is commonly facilitated by close contact in proximity driven by aggregation and 137 crowding of individuals, such as through aerosols (Radford et al., 2009; Thiry et al., 2009). In 
138 contrast to FIV, feline hemoplasma and Bartonella henselae are either transmitted during 139 reproductive behavior (FIV and feline hemoplasma) (Courchamp, Say \& Pontier, 2000; Willi et 140 al., 2007), or through arthropod vectors (B. henselae and feline hemoplasma) (Chomel et al., 2006;

141 Willi et al., 2007). Hence, the transmission modes of these three pathogens are assumed to be 142 relatively frequency-dependent (Thrall, Antonovics \& Hall, 1993). Lastly, FPV and Toxoplasma 143 gondii are pathogens mostly transmitted through environmental contaminants rather than direct 144 contact between infectious and susceptible individuals. As environmental feces concentration, 145 which function as common point source of exposure for environmentally-transmitted pathogens, 146 is expected to increase in relation to population density, we also assume the positive association 147 between the transmission of FPV and T. gondii with host population density. In summary, we 148 hypothesize that supplemental feeding would increase the population density of stray cats, leading 149 to heighted prevalence of pathogens transmitted through direct contact with infectious individuals 150 or with environmental contaminants (density-dependent transmission: FCV, FHV-1 and FeLV; 151 environmental transmission: FPV and T. gondii) (Lutz et al., 2009; Radford et al., 2009; Thiry et 152 al., 2009; Ballash et al., 2015). Meanwhile we expect that the prevalence of sexually-transmitted, 153 vector-borne, or trophically-transmitted pathogens (frequency-dependent transmission: T. gondii, 154 FIV, hemoplasma and B. henselae) would be relatively unaffected by difference in host population 155 density and supplemental feeding (Courchamp, Say \& Pontier, 2000; Willi et al., 2007; Chomel et 156 al., 2009; Afonso et al., 2013).

Table 1. Transmission modes of studied pathogens. Specific transmission routes of 159 studied pathogens and its relative position along the continuum between density-dependent and 160 frequency-dependent transmission 


\section{Methods and Materials}

\section{Study area}

The study was performed in Seoul, the capital city of the Republic of Korea (ROK). Seoul

165 is one of the largest megacities in the world with a population size and density of approximately

$1669,908,000$ and 17,000 people per $\mathrm{km}^{2}$, respectively (Kim \& Baik, 2005). The city has a temperate

167 climate with four seasons and an average temperature of $13.2{ }^{\circ} \mathrm{C}$ in the spring and fall, $24.3{ }^{\circ} \mathrm{C}$ in

168 the summer and $-2.4{ }^{\circ} \mathrm{C}$ in the winter. Cat ownership is rapidly increasing in the ROK, and

169 according to a recent national survey, cat ownership increased from $1.7 \%$ in 2010 to $3.4 \%$ in 2012

170 and to 5.2\% in 2015 (Animal and Plant Quarantine Agency, 2015). Most owned cats in Seoul are

171 kept indoors due to hygienic reasons and the fear of mortality from vehicle collisions. Hence free-

172 roaming cats in the city are commonly considered as unowned, stray cats. In the city, stray cats are

173 most commonly observed in residential areas including apartment complexes and intensive

174 housing areas.

175 Seoul is divided into 25 administrative local districts. We ranked the districts based on the

176 intensity of the cat caretaker activity (denoted hereafter as CCA) of each district. To rank all 25

177 districts based on the intensity of the CCA, we selected parameters that reflect the following

178 features: spatiotemporal regularity of the feeding behavior, socioeconomic characteristics related

179 to the cat feeding behavior, the number of cat caretakers and the number of cats cared for per

180 caretaker. In total, we used eight parameters, and information on six of those parameters were

181 extracted from the result of a 2013 nationwide cat-caretaker questionnaire (Seoul; n=1048) (Kim

$182 \mathrm{~J}$ et al., 2016) as follows: (1) proportion of survey respondents who identified themselves as cat

183 caretakers in the total population of each district, (2) proportion of respondents who are taking care 
184 of more than 10 cats, (3) proportion of respondents who have been working as a cat caretaker for

185 more than five years, (4) proportion of respondents who provide food supplement daily in a regular

186 manner, (5) proportion of respondents who provide food in areas further than 100 meters radius

187 from their house, and (6) a score from the subjective perception of each respondent about the

188 intensity of the CCA in his/her residing district. In addition, we included two more demographic

189 factors for each district, (7) matriculation rates and (8) property tax (index of wealth), which are

190 known to be positively associated with the intensity of the CCA in a previous study (Finkler, Hatna

$191 \&$ Terkel, 2011b). Second, we performed a principal component analysis of these eight parameters.

192 The first principal component (PC1) explained 39\% of the variance in the data (Table 2), and all

193 the parameters explaining the intensity of the CCA correlated positively with the PC1. Hence, the

194 PC1 was used as the index reflecting intensity of the CCA and the 25 city districts were ranked 195 based on this index (Fig 1).

Table 2. Principal components (PC1 and PC2) eigenvalues and PC loadings for the CCA

parameters.

199

200 Out of eight districts with highest or lowest CCA based on the ranking (Fig. 1), we excluded two 201 districts, one with high CCA (Songpa; SP) and the other with low CCA (Gangdong; GD), for 202 different reasons. SP is a unique district extensively consisting of many apartment complexes 203 where each apartment complex has their own specific policy on how to deal with stray cats 204 (trapping and euthanizing, poisoning, active cat caretaker activity etc.). Therefore, we assumed it 205 would be inappropriate to compare cat populations from SP with other districts; it was excluded 206 from this study. On the other hand, district GD was excluded due to unique local condition 
207 regarding stray cats. Although GD scored low in our CCA index, the district office and cat 208 caretakers of GD have been working in cooperation to systemically provide food for stray cats in 209 its district for years. For instance, they established various official feeding sites within the district 210 for stray cats. Hence, despite the low CCA of GD, the feeding ecology of stray cats within the 211 district may differ from other districts with similar CCA and were excluded from this study. Hence, 212 six remaining districts were used as our study sites, three with a high CCA (Gangnam; GN, Seocho; 213 SC, Mapo; MP) and three with a low CCA (Geumcheon; GC, Seongdong; SD, Dongdaemoon; 214 DDM)(Fig 1). Hereafter the three high CCA sites will be labeled as GN (H), SC (H) and MP (H), 215 and three low CCA sites as GC (L), SD (L) and DDM (L).

216

217 Fig 1. CCA (PC1) in the districts of Seoul based on the PCA result.

218 The six districts selected are; GN, SC and MP on the upper right side (high CCA districts; yellow), 219 and GC, DDM and SD on the lower left side (lower CCA districts; blue). District SP and GD was 220 excluded from the study site due to logistical reasons.

221 
222 Fig 2. Map of Seoul showing the 6 districts where the study was performed ${ }^{1}$

223 High CCA districts in red letters and low CCA districts in blue letters.

224

225 Field surveys

226 We performed population density surveys at 12 sites from the six selected districts (two

227 sites were selected in each district) (Fig 2). Due to logistical reasons, a survey of four sites (two 228 high CCA sites from district SC (H), and two low CCA sites from district GC (L)) was conducted 229 in the fall (September-November) of 2014 and the rest of the sites in the spring (April-June) of 230 2015. At each site, one survey transects of $2 \mathrm{~km}$ was established from the residential areas within 231 each district. Apartment complexes were excluded from the survey routes to prevent sampling bias 232 because different apartment complexes tend to have specific stray cat management policies. Each 233 transect was surveyed five times, once per day for five days, all within two weeks period. Typical 234 residential areas in the city used for the density survey consisted of rows of multistory houses 235 (usually 2-4 stories) constructed parallel to each other with a narrow alley in between (S1 Fig.). At

\section{We modified a source figure produced by 'Stefan-Xp' under the following copyright}

permission. 'Permission is granted to copy, distribute and/or modify this document under the terms of the GNU Free Documentation License, Version 1.2 or any later version published by the Free Software Foundation; with no Invariant Sections, no Front-Cover Texts, and no Back-Cover Texts. A copy of the license is included in the section entitled the GNU Free Documentation License. The GNU Free Documentation License (GNU FDL or simply GFDL) is a copyleft license for free documentation, designed by the Free Software Foundation (FSF) for the GNU Project.' 
236 each site, the transect routes were selected in a zig-zag configuration to thoroughly cover the

237 blocks, as in methods used in previous studies (Calhoon \& Haspel, 1989; Finkler, Hatna \& Terkel,

238 2011a). Alleys were walked by the same person throughout the survey (JH). Surveys were started

239 within one hour from sunset and usually completed within 60-70 min. These times were selected

240 based on the nocturnal characteristics of the cat activity (Izawa, 1983; Horn et al., 2011). All the

241 cats observed in the alleys were recorded as well as the ones on the roofs and walls of houses on 242 the both sides of the alleys. Due to the dense structure of the houses in these area, the lateral view

243 from the alleys was limited, and in most cases, the observer was only able to see the walls and the

244 roof top of the houses right next to the alleys. Only cats spotted near the observer, approximately

245 within two meters of range, close enough to identify its full morphological characters, were

246 counted and recorded. For every cat observed, the location, time of observation, and unique

247 characteristics (morphological features, behavior toward survey personnel, health status based on

248 external observation, and sex when possible) were recorded. Individual cats were primarily

249 identified by their coat color. A detailed coat pattern was depicted at the observed site on a record

250 sheet printed with outlines of cat body forms in various angles and postures. Cats with completely

251 uniform color throughout their body were very rare (eight out of 277 total observed cats), mostly

252 observed at different sites and were identified by other characteristics such as body size, tail shape,

253 or hair length. Data on the sterilization of the cats were identified and recorded by the ear-cut mark

254 made during the sterilization procedure. In Seoul, sterilized stray cats are marked with a straight

255 cut of the ear-tip, rather than a notch, which is easily identified by its abrupt shape. During this

256 survey, we did not observe any cat with physical scars that would be confused with the ear mark.

257 Kittens that were accompanied by their mother were not included in the density analysis. We did

258 not observe any kittens roaming by themselves during our surveys. 
259 Biological sample collection

Biological samples were collected from the 6 study districts (GN, SC, MP (high CCA) and

261 GC, DDM and SD (low CCA)) from September, 2014 to June, 2015 except for the cold season

262 (from December, 2014 to March, 2015) when Trap-Neuter-Release (TNR) is not done. The time

263 frame of the sample collection overlapped with that of the field density survey. The Seoul

264 Metropolitan Government has been performing TNR since 2008 as part of official city service. In

265 each district, designated animal hospitals perform TNR of stray cats under a contract with the

266 Seoul city government. We cooperated with animal hospitals from the six districts we selected and

267 requested that they collect 50 adult cat blood samples per district during the sterilization

268 procedures (Yeonnam Animal Hospital, MP (H); Hanbit Animal Hospital, SD (L); Kang Hyunrim

269 Animal Hospital, GC (L); Gangnam 24hr Animal Hospital, GN (H); Han Animal Hospital, SC (H)

270 and Jeonnong Animal Hospital, DDM (L)). All blood samples were drawn after the sterilization

271 surgery by certified veterinarians at each animal hospital. The protocol explaining the preferred

272 site and volume for the blood draw (jugular vein) and the data sheet to input the types of

273 information required for this study were provided to the veterinarians in advance with the syringes

274 and tubes required for our sample collection. All procedures were performed under full anesthesia

275 of the animal with a combination of Ketamine $(22 \mathrm{mg} / \mathrm{kg})$ and Xylazine $(1.1 \mathrm{mg} / \mathrm{kg})$ injected

276 through the hind leg muscle. All the cats that were determined to be yearlings or younger by the

277 veterinarians and were released without being sterilized; hence, no samples were collected from

278 these individuals.

279 Half of each blood sample (approx. 1.5-2ml) was placed into a tube containing the 280 anticoagulant ethylene diamine tetra-acetic acid (EDTA; Becton Dickinson, Rutherford, New 281 Jersey, USA), and the other half was placed into a serum separator tube. Blood samples collected 
282 for serum separation were permitted to clot and then centrifuged for $10 \mathrm{~min}$ at $1200 \mathrm{rcf}$ (relative

283 centrifugal force). Next, the serum was removed from the clot using a sterile pipet and transferred

284 to a sterile $1.5 \mathrm{ml}$ Eppendorf tube. All serum and whole blood samples were stored at $-70^{\circ} \mathrm{C}$ until

285 analyses were conducted.

\section{Laboratory analysis}

PCR was used to identify feline hemoplasma in the whole blood samples. Frozen whole

288 blood samples were thawed at room temperature and genomic DNA was extracted using the 289 QIAamp DNA mini kit (Qiagen, Hilden, Germany). The extracted DNA was used as a template 290 for the subsequent PCR assay. We amplified a partial segment of the 16S rRNA gene of 291 mycoplasma species (including hemoplasma, which is the hemotropic mycoplasma) using the 292 universal primer set HBT-F (ATACGGCCCATATTCCTACG) and HBT-R 293 (TGCTCCACCACTTGTTCA) described in a previous study (Criado-Fornelio et al., 2003). Every 294 PCR run included a positive and negative control to detect bacterial contamination. Amplified 295 products were separated by electrophoresis on a 1.2\% agarose gel. PCR amplicons from the 296 positive samples were purified and prepared for direct sequencing. The sequence homology of the 297 sequenced 16S rRNA gene from the positive samples was examined using the BLAST software 298 (National Center for Biotechnology Information; available at: http://www.ncbi.nlm.nih.gov).

302 tube was thawed for a single analysis only to prevent repeated thawing and freezing of the samples.

303 Commercial ELISA test kits were used to detect (1) antibodies for FIV and FeLV p27 antigen 304 detection (SensPERT FeLV Ag/FIV Ab kit; VetAll ${ }^{\mathrm{TM}}$ ) and (2) antibodies for T. gondii (Rapid 
305 diagnostic test (RDT) developed by Chong et al. 2011, using recombinant SAG1 antigen.). Tests

306 to detect $B$. henselae antibodies were done with the indirect immunofluorescence (IFA) slides test

307 (Bartonella henselae IFA feline IgG antibody kit; Fuller laboratories). A titer of $>$ 1:64 IgG

308 immunoglobulins was considered positive for exposure to $B$. henselae. Lastly, modified in-house

309 ELISA kits (ImmunoComb, Feline VacciCheck, Biogal Galed Laboratories) were used to test for

310 FCV, FHV-1 and FPV antibodies. The ImmunoComb ${ }^{\circledR}$ test is based on the solid phase "dot"-

311 ELISA technology consisting of a comb-shaped plastic card. On each of the 12 teeth on the plastic

312 card, there are four spots as follows: FCV antigen is the lowest spot; FHV-1 antigen is next to the

313 lowest spot; FPV antigen is the second spot from the top; and the uppermost spot is the positive

314 reference. The titer of the positive index used to test for antibodies to each pathogen in

315 ImmunoComb was as follows: FPV antibodies at 1:80 in the hemagglutination-inhibition (H.I.)

316 reaction; FHV-1 antibodies at 1:16, and FCV antibodies equal to $1: 32$ in the virus neutralization

317 reactions. Tests for all antigens and antibodies were performed based on the protocols provided by

318 the manufacturers.

\section{Estimating population density}

The population density estimation was performed by counting of individual cats identified

321 by their morphological characteristics (Harihar Abishek et al., 2009; Finkler, Hatna \& Terkel,

322 2011a). Information of morphological characteristics were primarily recorded during direct

323 observation, but also collected by photographs taken during the survey. We used a capture-

324 recapture sampling technique: there was an initial capture during which each observed cat was

325 individually identified and recorded, and four consecutives 'recapture' surveys in which re-sighted

326 cats were counted as 'recapture'. Population estimation was done based on the closed population

327 model assuming there was limited immigration/emigration, birth, and death during the 2-week 
328 survey period (Gross et al., 2011). Using the program MARK (Cooch \& White, 2001), we built

329 four models, $\mathrm{M}_{0}, \mathrm{M}_{\mathrm{t}}, \mathrm{M}_{\mathrm{h}}$ and $\mathrm{M}_{\mathrm{th}}$, with different variables and assumptions. $\mathrm{M}_{0}$ is the null model

330 with the principal assumption that the probability of capturing an animal is constant over all

331 animals over all periods, while the heterogeneity model, $\mathrm{M}_{\mathrm{h}}$, permits the capture probability to

332 vary for each individual. $\mathrm{M}_{\mathrm{t}}$ assumes each animal has a constant capture probability on any

333 sampling occasion; however, the probability of capture can vary from one occasion to the next

334 (Seber, 1992). Finally, model $\mathrm{M}_{\mathrm{th}}$ simultaneously assumes the heterogeneity in the capture

335 probability among individuals and between sampling occasions. Another trap response model

336 commonly used is $\mathrm{M}_{\mathrm{b}}$ which captures the variation of the individual response to previous trapping

337 (e.g., trap-shy and trap-neutral). However, this model was not used in our analysis because our

338 survey was based on capturing cats visually rather than physical trapping, and we did not consider

339 our visual observation as a likely source of behavioral variation. We evaluated the relative fit of

340 the models using the sample-size-adjusted Akaike Information Criterion $\left(\mathrm{AIC}_{\mathrm{c}}\right)$ index $($ Burnham

$341 \&$ Anderson, 1998). The model with the best fit was selected based on its $\mathrm{AIC}_{\mathrm{c}}$ values, delta $\mathrm{AIC}_{\mathrm{c}}$

342 and $\mathrm{AIC}_{\mathrm{c}}$ weight. For each site, the population size was obtained as the derived parameter of the

343 best fit model based on the $\mathrm{AIC}_{\mathrm{c}}$ model selection. The total number of individuals observed at each

344 site was multiplied by the size of the survey area to obtain estimates of the cat density (per $\mathrm{km}^{2}$ )

345 and 95\% confidence intervals. Survey areas were determined in ArcView 9.0 (ESRI, Redlands,

346 CA) by creating a polygon with a 50-meter buffer zone around each survey transect. The length of

347 the buffer zone was based on the result from a recent study on the home range of urban free-

348 roaming cats using GPS tracker, where the smallest home range size was 0.99ha.(Thomas, Baker

$349 \&$ Fellowes, 2014). This home range being equivalent to a circular area of dimeter of 350 approximately $55 \mathrm{~m}$, we used 50 meters as our buffer zone as a conservative estimate. The 
351 resulting size of the survey sites ranged from $0.13-0.20 \mathrm{~km}^{2}$. The population density estimated

352 from 2 sites within each district was averaged to enable the analysis of each district's association

353 with the prevalence of tested pathogens.

\section{Statistical analysis}

All statistical analyses were performed with R (http://cran.r-project.org). Chi-square tests

were done to ensure that there was no sex bias in the blood sample size among the six districts.

357 The normality of the population density of the 12 survey sites were confirmed through Shapiro-

358 Wilk tests. Two linear mixed-models (LMMs) were used to test the associations between the CCA 359 and the population density or the sterilization rates. In each model, the population density or the 360 sterilization rates were set as a response variable. In both models, the CCA was set as the 361 explanatory variable, and 'district' and 'year (density survey done in 2014 or 2015)' were set as random effects. We also tested for the presence of associations between the prevalence of each pathogen (response variable) and sex, population density (pd), and CCA using generalized linear models (GLMs) with the logit link function. None of the interaction factors showed a significant effect on the response variable (prevalence of each pathogen) and were not added to the analysis.

For the above statistical analyses, we considered a p-value of $\leq 0.05$ as significant. We used a

model selection approach (AICc) to determine the best model or suite of models (Burnham \& Anderson, 1998). For each pathogen, we did model-averaging for most parsimonious models (delta AICc smaller than 2 units) to further analyze the estimates of the model parameters. Analyses were performed using R package 'AICmodav' and 'Ime4' (Bates et al., 2015; Mazerolle, 2017).Lastly,

371 we calculated the mean and standard deviation of the stray cat sterilization rates in studied districts. 372 


\section{Results}

Across the 12 survey sites we observed a total of 276 cats during 60 surveys. The estimated

375 number of cats at each survey site ranged from 132 individuals to 268 individuals per $\mathrm{km}^{2}$, with 376 mean 186.8 per $\mathrm{km}^{2}$ (Table 3). However, two replicate sites from the same district showed a similar

377 number of estimated cats, although in two districts (DDM (L), GC (L)), the gap between the 378 replicate sites within each district was rather large (DDM (L) 1 and DDM (L) 2 had 132 and 175 379 individuals $/ \mathrm{km}^{2}$; GC (L) 1 and GC (L) 2 had 168 and 231 individuals/ $\mathrm{km}^{2}$ ), implying a possible 380 heterogeneity in the abundance of stray cats within the districts (Fig. 3). There was no association 381 between the population density and CCA (LMM; Wald $\chi 2=1.06, p=0.30)$ although trends for a 382 higher population density in low CCA districts (GC (L), SD (L)) and a lower population density 383 in high CCA districts $(\mathrm{GN}(\mathrm{H}), \mathrm{MP}(\mathrm{H}))$ were observed. Based on the observation of the TNR ear 384 marking, the proportion of sterilized cats ranged from $0-0.68$ with overall average of 0.23 . High 385 CCA districts had a significantly higher proportion of sterilized cats $(0.36 \pm 0.22)$, compared to 386 that of the low CCA districts $(0.10 \pm 0.09)(\mathrm{LMM}$; Wald $\chi 2=7.34, p<0.01$; Table 3$)$.

387 Fig 3. Cat population density estimates (95\% confidence intervals) from the 12 survey sites. 388

Table 3. Estimated population densities (95\% confidence intervals) and proportion of observed cats with the sterilization mark from the six districts (CCA indicated in parenthesis; high-H, low-L)

392

393 Blood samples collected for pathogen prevalence testing showed no sex bias among the six 394 districts $\left(\chi^{2}=7.25 ; p=0.20 ;\right.$ d.f. $\left.=5\right)$. The overall prevalence of the pathogens was relatively high 395 for FCV (94.3\% (282/299)), FHV-1 (97.9\% (293/299)) and FPV (79.2\% (236/298)) but low for 
396 the rest of the pathogens: T. gondii, 7.7\% (23/298); FIV, 3.6\% (11/302); FeLV, 23.2\% (70/302),

397 B. henselae, 34.8\% (105/302); and feline hemoplasma, 32.5\% (98/302). Among them, the FeLV

398 prevalence was highest in $\mathrm{GN}(\mathrm{H})$ and $\mathrm{SC}(\mathrm{H})$, both high CCA districts, whereas the FPV

399 prevalence was highest in DDM (L) and SD (L), followed by GC (L) which were the 3 low CCA

400 districts (Table 4).

401

402

Table 4. Prevalence (\%), 95\% confidence interval and sample size (n)) of each pathogen from

403

the stray cats in the six studied districts (Letter inside the parentheses indicates the CCA of

404 each district; H-high, L-low)

405 For all the pathogens, multiple models fell within $2 \Delta \mathrm{AICc}$ units (hereafter 'best models') (Table

5), and all three explanatory variables were included within these models, except for FPV.

407

However, based on the magnitude and direction of the parameter estimates, different variables

408 showed unique associations with the prevalence of each pathogen (Table 6). For FeLV, the two

409 best fit models (Akaike weight $=0.62$ and 0.25 ) was composed of sex and CCA, and based on the

410 estimates of both parameters, the prevalence of FeLV was significantly higher in high CCA

411 districts and in females. Meanwhile, both of the two best models for the FPV prevalence with the

412 highest AICc weights (0.39 and 0.33) included the CCA parameter. According to the parameter

413 estimates, the prevalence of FPV in the low CCA districts is likely to be approximately three times

414 higher than that of the high CCA districts; showing and opposite pattern with FeLV. For

415 hemoplasma, sex was included in all three best models (Akaike weight $=0.35,0.33$ and 0.17 ), and

416 the parameter estimates showing that males contracting hemoplasma infection would be

417 approximately 2.23 times higher compare to females. Similarly, sex was the only variable included

418 in all top three models (Akaike weight $=0.34,0.26$ and 0.13 ) for $T$. gondii; however, its relationship 
419 with prevalence was in the opposite direction for which females had three times higher odds of $T$.

420 gondii infection. FCV was the only pathogen for which the population density parameter was

421 consistently included in the three best models (Akaike weight 0.38, 0.31 and 0.16 ), and its

422 prevalence showed a negative relationship with the population density. Regarding FHV, all top

423 four models included the variable CCA; however, its influence on the FHV prevalence remains

424 unverified based on its 95\% confidence interval which included a zero and non-significant $p$ -

425 value $(\mathrm{P}=0.99)$. In the model evaluation of the last two pathogens, FIV and $B$. henselae, none of

426 the top models shared a variable. In the parameter estimates, 95\% confidence intervals of all three

427 variables included zero, and the variables did not show any significant influence on the infection

428 status of FIV or B. henselae (Table 6).

429

430

Table 5. AICc values and AICc weights of the most parsimonious candidate models (models

within 2 units of the $\triangle \mathrm{AICc}$ ) testing the effect of the explanatory variables (sex, population

density (pd) and CCA) on the prevalence of the eight studied pathogens.

433

434

Table 6. Model-averaged parameter estimates included in the most parsimonious models

(models within 2 units of the $\triangle \mathrm{AICc}$ ) for each pathogen

\section{Discussion}

438 In contrast to our hypothesis, the population density of cats did not show a positive relationship 439 with the intensity of the CCA. Instead, the population density of the cats was lower in the high 440 CCA districts although the association was not statistically significant (Fig. 3). This trend may be 
441 explained by the difference in the proportion of sterilized cats among the districts as evidenced by

442 the higher proportion of ear-marked cats in the high CCA districts in our observation. In certain

443 districts, cat caretakers are known to heavily contribute to sterilizing stray cats in addition to the

444 TNR done by the Seoul government as result of aggressive campaigning and education. The two

445 high CCA districts $(\mathrm{GN}(\mathrm{H})$ and $\mathrm{SC}(\mathrm{H}))$ are the districts with the highest income in the city which

446 is a socioeconomic factor that is known to be linked to either the proportion of sterilized stray cats

447 or the level of sterilization by the caretakers (Finkler, Hatna \& Terkel, 2011a,b; Flockhart, Norris

$448 \&$ Coe, 2016). This is also supported by the result of the cat caretaker survey done in the ROK

449 (Kim J et al., 2016), in which GN (H), SC (H) and MP (H) were among the top five districts

450 regarding the proportion of cat caretakers with experience of sterilizing stray cats. Thus, although

451 stray cats from the districts with a higher CCA may be exposed to more frequent and stable

452 supplemental feeding, it is likely that more cats in these areas are also sterilized resulting in smaller

453 population sizes compared to districts with a lower CCA.

454 From the eight studied pathogens, different associations were observed for each pathogen

455 in relation to the population density and CCA. In three pathogens, FCV, FHV-1 and FeLV, with a

456 transmission mode considered to rely on close contact of the host individuals (density-dependent

457 transmission), we predicted its prevalence to be higher in a high CCA district due to higher

458 population density. However, the pattern of association varied among these three pathogens. A

459 significant link was observed between FeLV and CCA and between FCV and population density,

460 whereas no single variable had a strong influence on explaining the prevalence of FHV-1. FCV

461 and FHV-1 are two of the main pathogens causing feline respiratory tract disease and can

462 especially be important in conditions where cats live socially. Compared to previous

463 seroprevalence reports on pets or shelter cats (FCV, 36.6-92.4\%; FHV-1, 11-73.3\%) (Lappin et 
464 al., 2002; Lickey et al., 2005; DiGangi et al., 2012), results from our study were in a higher range 465 for both FCV (95\%) and FHV-1 (97.3\%). However, Yamaguchi et al. (1996) reported high 466 seroprevalence values for both FCV and FHV-1 (FCV, 100\%; FHV-1, 100\%) in a study of free467 roaming farm cats, that shared supplemental food and latrine sites which is a condition perhaps 468 more similar to our study setting compared to the other studies. Considering that both viral 469 pathogens are highly contagious among cats in immediate proximity (Bannasch \& Foley, 2005; 470 Radford et al., 2009; Thiry et al., 2009), aggregation of individuals in close contact and/or higher 471 survival rates of individuals after infection, driven by supplemental feeding (Lembo et al., 2011; 472 Bitew et al., 2011; DiGangi et al., 2012), may have contributed to the high seroprevalence of FCV 473 or FHV-1 observed in the study by Yamaguchi et al. (Yamaguchi et al., 1996) and in our study.

474 Nevertheless, the negative relationship of the FCV prevalence with population density was 475 unexpected. We suspect that external variables may be involved in the observed relationship, such 476 as a possibility of higher mortality in cats due to hypervirulent FCV infection in dense populations 477 (Radford et al., 2007).

In the case of FeLV, its prevalence was significantly higher in districts with a high CCA 479 (with GN and SC exhibiting the highest FeLV prevalence), but unrelated to the population density 480 481 2011; Stojanovic \& Foley, 2011), we observed a relatively high prevalence (12-42\%), especially of stray cats. In comparison to previous studies on FeLV (2-23\%) (Levy et al., 2006; Alves et al., 482 in two of our studied districts (GN $(\mathrm{H})$ and SC (H)). Unlike FCV or FHV-1, transmission of FeLV 483 relies less on aerosol or fomite, and its ability to survive outside the host is low (Lutz et al., 2009). 484 Instead, it readily transmits through immediate amicable contacts such as food sharing, licking, 485 and grooming (Rojko \& Olsen, 1984; Barratt, 1997). We suggest that the higher FeLV prevalence 486 in the two districts with a high CCA may be due to increased aggregation of cats around food 
487 provisioned by the cat caretakers. A recent simulation study demonstrated that increased 488 aggregation and population density of supplemented cats led to a higher FeLV prevalence, 489 although such impact varied depending on the influence of provisioned food on the immune 490 response of cats (Becker \& Hall, 2014). Considering the potential fatality of FeLV infection, we 491 suggest further studies to clarify the long-term effect of providing supplemental food on stray cat 492 populations.

For two pathogens with environmental transmission, T. gondii and FPV, we also predicted

494 its prevalence to be positively associated with the population density of cats. In the case of $T$. 495 gondii, the overall number of positive individuals was low in general (Table 3), similar to other 496 studies on $T$. gondii prevalence in urban stray cats, which ranged from 5.61-14.3\% (Lee et al., 2011; Wang et al., 2012; Oi et al., 2015). Additionally, its prevalence did not show any significant 498 association with population density or CCA. Unlike feral cats in rural areas, where the prevalence of $T$. gondii in cats have been reported to be associated with the predation of intermediate host 500 species (Afonso et al., 2007), transmission of $T$. gondii is more likely related to direct contact with 501 oocysts in urban cat populations (Lelu et al., 2010). However, even within urban stray cats, fed 502 populations are more likely to consume processed cat food, devoid of infectious T. gondii oocysts, 503 while unfed populations would be more prone to rely on hunted prey that may function as 504 intermediate hosts. Considering the potential risk that $T$. gondii may pose on public health as a 505 zoonotic pathogen, we need to better understand the transmission dynamics of $T$. gondii between 506 stray cats and those who are fed or interact closely with them on a daily basis.

507 The prevalence of FPV in our study ranged from 59-94\%. The prevalence of FPV was 508 highest in two districts with the lowest CCA (GC (L) and SD (L)) but showed a non-significant 509 association with the host population density. Feline parvovirus (FPV), the etiologic agent of feline 
510 panleukopenia, is a viral pathogen extremely resistant to external conditions enabling its

511 environmental transmission by contact with various biotic or abiotic materials contaminated with

512 fluids, fomites, or feces from an infected animal (Ikeda et al., 2002; Truyen et al., 2009). We

513 expected the prevalence of FPV to be related to the accumulation of viral contaminants in the

514 environment reflected by the population density in the area, but instead, the result indicated the

515 association of FPV prevalence with CCA. Lack of food provisioning by caretakers in low CCA

516 districts may have enabled stray cats in the area to maintain a larger activity range with a more

517 intensive foraging activity compared to conspecifics in the high CCA districts with a relatively

518 abundant and stable food source (Barratt, 1997; Tennent \& Downs, 2008). This altered foraging

519 strategy may lead to higher exposure rates of cats to pathogens transmitted by contact with

520 environmental contaminants (Lepczyk, Lohr \& Duffy, 2015). Similar associations have been

521 discussed in other systems such as in the case of the increased infection to Strongyloides in wild

522 primates (Parr, Fedigan \& Kutz, 2013).

523 Among the three pathogens selected for their frequency-dependent transmission mode,

524 FIV, B. henselae, and feline hemoplasma, none of the pathogens showed an association with CCA

525 or population density as initially predicted. The low prevalence of FIV (total prevalence: 3.6\%;

526 95\% C.I. 0.018-0.049) observed in this study has been commonly reported in other population-

527 level studies in free-roaming or household cats (Lee et al., 2002; Levy et al., 2006; Ravi et al.,

528 2010). FIV prevalence is most commonly explained in relation to the breeding ecology of free-

529 roaming cats (Natoli et al., 2005; Fouchet et al., 2009). Urban stray cats are known to maintain a

530 promiscuous mating system due to the high local density of both male and female cats (unlike its

531 rural counterparts, wherein a polygynous mating system is observed (Pontier \& Natoli, 1996))

532 which may lead to fewer aggressive interactions between males during breeding seasons and an 
533 overall low prevalence of FIV in urban male cats (Courchamp, Say \& Pontier, 2000; Pontier et al.,

534 2009; Ravi et al., 2010). In addition, neutering/spaying may have an additional impact on lowering

535 the aggressive behavior related to breeding further influencing the prevalence of FIV in urban stray 536 cats.

538 density. However, considering that $B$. henselae is a zoonotic pathogen transmitted mostly through

539 fleas, and that transmission of fleas can be facilitated by a high host population density (Krasnov,

540 Khokhlova \& Shenbrot, 2002), further attention is required regarding the prevalence of $B$. henselae

541 in urban stray cats and its potential risk to cat caretakers. The prevalence of feline hemoplasma in

542 male cats was higher than in female cats, similar to results from previous studies. It may be due to

543 its transmission through aggressive sexual behavior (Walker Vergara et al., 2016; Bergmann et al.,

544 2017). Overall, the spread of vector-borne and sexually transmitted diseases, such as $B$. henselae,

545 feline hemoplasma, and FIV, are generally considered less impacted by the host population density

546 or close contact among host individuals and is further supported by the results presented here.

547 To summarize, the findings from this study did not support our original hypothesis. First

548 the population density and CCA did not show positive relationship, which was the fundamental

549 assumption of our study. This shows that urban animal populations whose life-history is heavily

550 interrupted by humans require consideration of multiple ecological and sociological factors to

551 understand their population dynamics. Second, the pathogens considered to use "density-

552 dependent transmission" modes, and originally expected to be positively related to CCA and host

553 population density, such as FCV, FHV, FeLV, T. gondii and FPV, mostly showed non-significant

554 responses toward the two factors or mixed responses to CCA. Specifically, only FeLV and FPV

555 showed significant relationships with CCA, but in different directions, with FeLV higher and FPV 
556 showing lower prevalence in higher CCA districts. This points out the possibility that in addition

557 to the effect of supplemented food, which can increase immediate crowding of animals, its 558 influence through other routes, such as altered foraging behavior, may also affect how these 559 animals interact with their pathogens.However, study results may be limited by small sample size 560 and the nature of convenience samples. Small sample size may have been especially problematic 561 for pathogens with relatively high (FCV and FHV) or low prevalence (T. gondii and FIV) in 562 throughout the studied districts. In addition, the samples used for pathogen testing were 563 opportunistically collected through TNR centers, rather than targeted sampling. Due to the lack of 564 exact overlap between cats surveyed for density analysis and cats used for pathogen testing, data used in this study may not be able to fully represent each other, although they were pooled and 566 interpreted as samples from same district. Future similar studies may benefit from not only a larger 567 sample size, but also by collecting samples specifically of the population where the density survey 568 was performed.

569 With an increasing population size of stray cats in many urban cities, concerns arise 570 regarding the impact of stray cats on the viability of wildlife populations and their potential role 571 in disease transmission between humans as well as domestic and wild animals (Longcore, Rich \& 572 Sullivan, 2009; Lepczyk, Lohr \& Duffy, 2015). In attempt to control the population size, 573 sterilization is commonly adopted in many countries. However, it is often overlooked that 574 sterilizing may also have an unexpected impact on the disease ecology of stray cat populations by 575 shifting various behavioral traits of individuals and/or demographic structures (Finkler \& Terkel, 576 2010; Finkler, Gunther \& Terkel, 2011). For instance, sterilized cats may have a reduced 577 aggressive or roaming behavior compared to intact cats and therefore have a reduced chance of 578 exposure and transmission of infectious pathogens (Scott et al., 2002; Finkler \& Terkel, 2010; 
579 Finkler, Gunther \& Terkel, 2011). In contrast, pathogens transmitted through amicable behavior

580 (e.g., conspecific grooming), such as FeLV, may be facilitated in populations where a high number

581 of cats are sterilized (Jeon JK, 2011). Immigration of cats into neutered cat populations has been

582 reported as a common occurrence (Gunther, Finkler \& Terkel, 2011; Kilgour et al., 2017) with the

583 potential risk of immigrants carrying and introducing pathogens. Currently, there is lack of

584 concrete information to verify the epidemiological impact of sterilizing cats. Hence, additional

585 efforts are warranted to clarify the impact of sterilization not only on the population control of

586 stray cats but also on the health and welfare of free-roaming cats overall.

587

\section{Conclusion}

In conclusion, our findings did not meet our initial assumption that population density would be lower in high CCA districts. Likewise, the relationships between pathogen prevalence

591 and population density or CCA varied for each tested pathogen rather than showing similar patterns depending on their transmission mode. Among the studied pathogens, only FPV and FeLV showed a significant association with the CCA but no association with population density. Our results suggest that supplemental feeding may influence disease ecology in the subject host population, not only by increasing the population density around the area as observed in previous studies on wildlife (Putman \& Staines, 2004; Geisser \& Reyer, 2005), but also by potentially

597 changing the behavior or biology of animals, such as an altered aggregation and foraging behavior, 598 which can affect their exposure and/or susceptibility to pathogens. So far, studies on urban stray 599 cats with an emphasis on health aspects have been mostly limited to screening for the prevalence 600 of zoonotic pathogens. However, we suggest that the incorporation of multifaceted information, 601 such as human behaviors and perceptions about urban stray cats, the influence of human behaviors 
602 on the ecology of cats and the transmission of pathogens of interest, would be crucial to better 603 understand the potential epidemiological risk that urban stray cats may pose to wildlife and/or 604 human public health and to design efficient management strategies.

605

\section{Acknowledgements}

607 We sincerely thank Daniel Becker, Dr. Jefferey Hepinstall-Cymerman, Dr. Annie Page-Karjian 608 and the anonymous reviewers for their insightful comments on the earlier versions of the 609 manuscript.

610 


\section{References}

612 Adelman JS., Moyers SC., Farine DR., Hawley DM. 2015. Feeder use predicts both acquisition

614 and transmission of a contagious pathogen in a North American songbird. Proceedings of 19 the Royal Society B: Biological Sciences 282. DOI: 10.1098/rspb.2015.1429. Fromont E. 2013. Environmental determinants of spatial and temporal variations in the transmission of Toxoplasma gondii in its definitive hosts. International Journal for

Ballash GA., Dubey JP., Kwok OCH., Shoben AB., Robison TL., Kraft TJ., Dennis PM. 2015.

625

626

Afonso E., Thulliez P., Pontier D., Gilot-Fromont E. 2007. Toxoplasmosis in prey species and Parasitology: Parasites and Wildlife 2:278-285. DOI: 10.1016/j.ijppaw.2013.09.006.

\section{8}

629

630

631

632 consequences for prevalence in feral cats: not all prey species are equal. Parasitology 134:1963-1971. DOI: 10.1017/S0031182007003320.

Animal and Plant Quarantine Agency 2015. National survey on public attitude toward animal protection. Anyang, Korea

Seroprevalence of Toxoplasma gondii in White-Tailed Deer (Odocoileus virginianus) and Free-Roaming Cats (Felis catus) Across a Suburban to Urban Gradient in Northeastern Ohio. EcoHealth 12:359-367. DOI: 10.1007/s10393-014-0975-2.

Bannasch MJ., Foley JE. 2005. Epidemiologic evaluation of multiple respiratory pathogens in cats in animal shelters. Journal of Feline Medicine \& Surgery 7:109-119. DOI: 10.1016/j.jfms.2004.07.004.

Barratt DG. 1997. Home Range Size, Habitat Utilisation and Movement Patterns of Suburban and Farm Cats Felis catus. Ecography:271. 
633 Bateman PW., Fleming PA. 2012. Big city life: carnivores in urban environments. Journal of

634

635

636

637

638

639

640

641

642

643

644

645

646

647

648

649

650

651

652

653

654 Zoology 287:1-23. DOI: 10.1111/j.1469-7998.2011.00887.x.

Bates D., Mächler M., Bolker B., Walker S. 2015. Fitting Linear Mixed-Effects Models Using lme4. Journal of Statistical Software; Vol 1, Issue 1 (2015).

Becker DJ., Hall RJ. 2014. Too much of a good thing: resource provisioning alters infectious disease dynamics in wildlife. Biology Letters 10. DOI: 10.1098/rsbl.2014.0309.

Becker DJ., Streicker DG., Altizer S. 2015. Linking anthropogenic resources to wildlifepathogen dynamics: a review and meta-analysis. Ecology Letters 18:483-495. DOI: 10.1111/ele.12428.

Begon M., Bennett M., Bowers RG., French NP., Hazel SM., Turner J. 2002. A clarification of transmission terms in host-microparasite models: numbers, densities and areas. Epidemiology and Infection 129:147-153.

Bergmann M., Englert T., Stuetzer B., Hawley JR., Lappin MR., Hartmann K. 2017. Risk factors of different hemoplasma species infections in cats. BMC veterinary research 13:52. DOI: 10.1186/s12917-017-0953-3.

Bitew M., Andargie A., Bekele M., Jenberie S., Ayelet G., Gelaye E. 2011. Serological survey of African horse sickness in selected districts of Jimma zone, Southwestern Ethiopia. Tropical animal health and production 43:1543-1547. DOI: 10.1007/s11250-011-98398.

Brennan A., Cross PC., Higgs MD., Edwards WH., Scurlock BM., Creel S. 2014. A multi-scale assessment of animal aggregation patterns to understand increasing pathogen seroprevalence. Ecosphere 5:1-25. DOI: 10.1890/ES14-00181.1. 
655 Burnham KP., Anderson DR. 1998. Practical Use of the Information-Theoretic Approach. In: 656 Burnham KP, Anderson DR eds. Model Selection and Inference: A Practical Information-Theoretic Approach. New York, NY: Springer New York, 75-117. DOI:

658 10.1007/978-1-4757-2917-7_3.

659 Calhoon RE., Haspel C. 1989. Urban Cat Populations Compared by Season, Subhabitat and 660 Supplemental Feeding. Journal of Animal Ecology 58:321-328. DOI: 10.2307/5003.

661 Centonze LA., Levy JK. 2002. Characteristics of free-roaming cats and their caretakers. Journal 662 of the American Veterinary Medical Association 220:1627-1633.

663 Chomel BB., Boulouis H-J., Breitschwerdt EB., Kasten RW., Vayssier-Taussat M., Birtles RJ., 664 665 Koehler JE., Dehio C. 2009. Ecological fitness and strategies of adaptation of Bartonella species to their hosts and vectors. Veterinary Research 40:29. DOI:

666 $10.1051 /$ vetres/2009011.

667

668

669

670

671

672

673

674

675

676

CHOMEL BB., KASTEN RW., HENN JB., MOLIA S. 2006. Bartonella Infection in Domestic Cats and Wild Felids. Annals of the New York Academy of Sciences 1078:410-415. DOI: 10.1196/annals.1374.080.

Cooch E., White G. 2001. Program Mark. A Gentle Introduction.(Colorado State University.) Available at http://www. phidot. org/software/mark/docs/book/[Verified 15 June 2011].

Courchamp F., Say L., Pontier D. 2000. Transmission of Feline Immunodeficiency Virus in a population of cats (Felis catus). Wildlife Research 27:603-611.

Criado-Fornelio A., Martinez-Marcos A., Buling-Sarana A., Barba-Carretero JC. 2003. Presence of Mycoplasma haemofelis, Mycoplasma haemominutum and piroplasmids in cats from southern Europe: a molecular study. Veterinary microbiology 93:307-317. 
677 DiGangi BA., Levy JK., Griffin B., McGorray SP., Dubovi EJ., Dingman PA., Tucker SJ. 2012.

678 Prevalence of serum antibody titers against feline panleukopenia virus, feline herpesvirus

679 1, and feline calicivirus in cats entering a Florida animal shelter. Journal of the American

680 Veterinary Medical Association 241:1320-1325. DOI: 10.2460/javma.241.10.1320.

681 Dobson A., Meagher M. 1996. The Population Dynamics of Brucellosis in the Yellowstone

682 National Park. Ecology 77:1026-1036. DOI: 10.2307/2265573.

683 Fabiana Alves, Daniela D.S. Rajao, Helen L.D. Puerto, Gissandra F. Braz, Romulo C. Leite,

684 Carlos Mazur, Almir S. Martins and Jenner K.P.D. Reis 2011. Occurrence of Feline

685 Immunodeficiency Virus and Feline Leukemia Virus Infection in Cats. American Journal

686 of Animal and Veterinary Sciences 6:125-129.

687 Fenton A., Fairbairn JP., Norman R., Hudson PJ. 2002. Parasite transmission: reconciling theory 688 and reality. Journal of Animal Ecology 71:893-905. DOI: 10.1046/j.1365-

689 2656.2002.00656.x.

690 Finkler H., Gunther I., Terkel J. 2011. Behavioral differences between urban feeding groups of

691

692 neutered and sexually intact free-roaming cats following a trap-neuter-return procedure.

693 Journal of the American Veterinary Medical Association 238:1141-1149. DOI:

694 10.2460/javma.238.9.1141.

695

Finkler H., Hatna E., Terkel J. 2011a. The influence of neighbourhood socio-demographic

696 factors on densities of free-roaming cat populations in an urban ecosystem in Israel. Wildlife Research 38:235-243.

697 Finkler H., Hatna E., Terkel J. 2011b. The Impact of Anthropogenic Factors on the Behavior, 698 Reproduction, Management and Welfare of Urban, Free-Roaming Cat Populations. 699 Anthrozoös 24:31-49. DOI: 10.2752/175303711X12923300467320. 
700 Finkler H., Terkel J. 2010. Cortisol levels and aggression in neutered and intact free-roaming 701 female cats living in urban social groups. Physiology \& behavior 99:343-347. DOI:

$702 \quad$ 10.1016/j.physbeh.2009.11.014.

703 Fischer C., Reperant LA., Weber JM., Hegglin D., Deplazes P. 2005. Echinococcus multlocularis 704 705 infections of rural, residential and urban foxes (Vulpes vulpes) in the canton of Geneva, Switzerland. Parasite (Paris, France) 12:339-346.

706 Flockhart DTT., Norris DR., Coe JB. 2016. Predicting free-roaming cat population densities in 707 urban areas. Animal Conservation 19:472-483. DOI: 10.1111/acv.12264.

708 Forristal VE., Creel S., Taper ML., Scurlock BM., Cross PC. 2012. Effects of supplemental 709 feeding and aggregation on fecal glucocorticoid metabolite concentrations in elk. The

710 Journal of Wildlife Management 76:694-702. DOI: 10.1002/jwmg.312.

711 Fouchet D., Leblanc G., Sauvage F., Guiserix M., Poulet H., Pontier D. 2009. Using Dynamic

712

713

714

715

716

717

718

719

720

721 Gerhold RW., Jessup DA. 2013. Zoonotic diseases associated with free-roaming cats. Zoonoses 722 Stochastic Modelling to Estimate Population Risk Factors in Infectious Disease: The Example of FIV in 15 Cat Populations. PLOS ONE 4:e7377. DOI: 10.1371/journal.pone.0007377.

Galbraith JA., Beggs JR., Jones DN., Stanley MC. 2015. Supplementary feeding restructures urban bird communities. Proceedings of the National Academy of Sciences 112:E2648E2657. DOI: 10.1073/pnas.1501489112.

Geisser H., Reyer H-U. 2005. The influence of food and temperature on population density of wild boar Sus scrofa in the Thurgau (Switzerland). Journal of Zoology 267:89-96. DOI: $10.1017 / \mathrm{S} 095283690500734 \mathrm{X}$. and Public Health 60:189-195. DOI: 10.1111/j.1863-2378.2012.01522.x. 
723 Greer AL., Briggs CJ., Collins JP. 2008. Testing a key assumption of host-pathogen theory:

724 density and disease transmission. Oikos 117:1667-1673. DOI: 10.1111/j.1600-

$725 \quad$ 0706.2008.16783.x.

726 Gross J., Elvinger F., Hungerford LL., Gehrt SD. 2011. Raccoon use of the urban matrix in the 727 Baltimore Metropolitan Area, Maryland. Urban Ecosystems 15:667-682. DOI:

$728 \quad$ 10.1007/s11252-011-0218-z.

729 Gunther I., Finkler H., Terkel J. 2011. Demographic differences between urban feeding groups

730 of neutered and sexually intact free-roaming cats following a trap-neuter-return

731 procedure. Journal of the American Veterinary Medical Association 238:1134-1140.

732 DOI: $10.2460 /$ javma.238.9.1134.

733 Harihar Abishek, Ghosh Mousumi, Fernandes Merwyn, Pandav Bivash, Goyal Surendra P. 2009.

$734 \quad$ Use of photographic capture-recapture sampling to estimate density of Striped Hyena

735 (Hyaena hyaena): implications for conservation. mammalia 74:83. DOI:

$736 \quad 10.1515 / \mathrm{mamm} .2009 .072$.

737 Horn JA., Mateus-Pinilla N., Warner RE., Heske EJ. 2011. Home range, habitat use, and activity 738 patterns of free-roaming domestic cats. The Journal of Wildlife Management 75:1177-

739 1185. DOI: $10.1002 /$ jwmg. 145 .

740 Ikeda Y., Nakamura K., Miyazawa T., Tohya Y., Takahashi E., Mochizuki M. 2002. Feline Host 741 Range of Canine parvovirus: Recent Emergence of New Antigenic Types in Cats.

742 Emerging Infectious Diseases 8:341-346. DOI: 10.3201/eid0804.010228.

743 Izawa M. 1983. Daily Activities of the Feral Cat Felis catus LINN. Journal of the Mammalogical $744 \quad$ Society of Japan 9:219-228. DOI: 10.11238/jmammsocjapan1952.9.219. 
745 Jeon JK 2011. Social organization and behavioiural patterns of a neutered feral cat colony in an 746 urban environment (Felis catus).

747 Jessop TS., Smissen P., Scheelings F., Dempster T. 2012. Demographic and Phenotypic Effects 748 of Human Mediated Trophic Subsidy on a Large Australian Lizard (Varanus varius):

749 Meal Ticket or Last Supper? PLoS ONE 7:e34069. DOI: 10.1371/journal.pone.0034069.

750 Kilgour RJ., Magle SB., Slater M., Christian A., Weiss E., DiTullio M. 2017. Estimating free751 roaming cat populations and the effects of one year Trap-Neuter-Return management

752

753 effort in a highly urban area. Urban Ecosystems 20:207-216. DOI: 10.1007/s11252-016-

754 Kim Y-H., Baik J-J. 2005. Spatial and Temporal Structure of the Urban Heat Island in Seoul. 755 Journal of Applied Meteorology 44:591-605. DOI: 10.1175/JAM2226.1.

756 Kim J, Hwang JS, MS Min, Chun MS, Lee H 2016. Socioeconomic characteristics and cat 757 caretaking behavior of cat caretakers in Korea. Journal of Korean Veterinary Medical Association.

759 Krasnov B., Khokhlova I., Shenbrot G. 2002. The Effect of Host Density on Ectoparasite 760 Distribution: An Example of a Rodent Parasitized by Fleas. Ecology 83:164-175. DOI:

761 $10.2307 / 2680129$

762

763

Lappin MR., Andrews J., Simpson D., Jensen WA. 2002. Use of serologic tests to predict resistance to feline herpesvirus 1 , feline calicivirus, and feline parvovirus infection in cats. Journal of the American Veterinary Medical Association 220:38-42.

765 Lee S-E., Kim N-H., Chae H-S., Cho S-H., Nam H-W., Lee W-J., Kim S-H., Lee J-H. 2011. 766 Prevalence of Toxoplasma gondii Infection in Feral Cats in Seoul, Korea. Journal of Parasitology 97:153-155. DOI: 10.1645/GE-2455.1. 
768 Lee IT., Levy JK., Gorman SP., Crawford PC., Slater MR. 2002. Prevalence of feline leukemia 769 virus infection and serum antibodies against feline immunodeficiency virus in unowned 770 free-roaming cats. Journal of the American Veterinary Medical Association 220:620$771 \quad 622$.

772 Lelu M., Langlais M., Poulle M-L., Gilot-Fromont E. 2010. Transmission dynamics of 773 Toxoplasma gondii along an urban-rural gradient. Theoretical population biology $774 \quad$ 78:139-147. DOI: 10.1016/j.tpb.2010.05.005.

775 Lembo T., Hampson K., Auty H., Beesley CA., Bessell P., Packer C., Halliday J., Fyumagwa R., 776 Hoare R., Ernest E., Mentzel C., Mlengeya T., Stamey K., Wilkins PP., Cleaveland S. 777 2011. Serologic Surveillance of Anthrax in the Serengeti Ecosystem, Tanzania, 1996778 2009. Emerging Infectious Diseases 17:387-394. DOI: 10.3201/eid1703.101290.

779 Lepczyk CA., Lohr CA., Duffy DC. 2015. A review of cat behavior in relation to disease risk 780

781 and management options. Applied Animal Behaviour Science 173:29-39. DOI: 10.1016/j.applanim.2015.07.002.

782 Levy JK., Scott HM., Lachtara JL., Crawford PC. 2006. Seroprevalence of feline leukemia virus 783 and feline immunodeficiency virus infection among cats in North America and risk factors for seropositivity. $J$ Am Vet Med Assoc 228. DOI: 10.2460/javma.228.3.371. the Petén Region of Guatemala. Journal of Zoo and Wildlife Medicine 36:121-123.

787 Longcore T., Rich C., Sullivan LM. 2009. Critical assessment of claims regarding management 788 of feral cats by trap-neuter-return. Conservation Biology: The Journal of the Society for Conservation Biology 23:887-894. DOI: 10.1111/j.1523-1739.2009.01174.x. 
790 López-Bao JV., Palomares F., Rodríguez A., Delibes M. 2010. Effects of food supplementation

791 on home-range size, reproductive success, productivity and recruitment in a small

792 population of Iberian lynx. Animal Conservation 13:35-42. DOI: 10.1111/j.1469-

$793 \quad$ 1795.2009.00300.x.

794 Lutz H., Addie D., Belak S., Boucraut-Baralon C., Egberink H., Frymus T., Gruffydd-Jones T., 795 Hartmann K., Hosie MJ., Lloret A., Marsilio F., Pennisi MG., Radford AD., Thiry E., 796 Truyen U., Horzinek MC. 2009. Feline leukaemia. ABCD guidelines on prevention and management. Journal of feline medicine and surgery 11:565-574. DOI:

799

Mazerolle MJ. 2017. AICcmodavg: Model Selection and Multimodel Inference Based on

800 (Q) $A I C(c)$.

801 Miller R., Kaneene JB., Fitzgerald SD., Schmitt SM. 2003. Evaluation of the influence of 802 803

804 supplemental feeding of white-tailed deer (Odocoileus virginianus) on the prevalence of bovine tuberculosis in the Michigan wild deer population. Journal of Wildlife Diseases

805

806

807

808

809

810

811 Natoli E., Say L., Cafazzo S., Bonanni R., Schmid M., Pontier D. 2005. Bold attitude makes 812

Moyers SC. 2017. Behavioral Heterogeneity and Disease Dynamics in House Finches (Haemorhous mexicanus). Doctoral Dissertation Thesis. Virginia Polytechnic Institute and State University.

Murray MH., Becker DJ., Hall RJ., Hernandez SM. 2016. Wildlife health and supplemental feeding: A review and management recommendations. Biological Conservation 204, Part B:163-174. DOI: 10.1016/j.biocon.2016.10.034. male urban feral domestic cats more vulnerable to Feline Immunodeficiency Virus. 39:84-95. DOI: 10.7589/0090-3558-39.1.84. 
Individual differences in behavior and physiology; causes and consequences 29:151-157.

814 DOI: 10.1016/j.neubiorev.2004.06.011.

815 Oi M., Yoshikawa S., Maruyama S., Nogami S. 2015. Comparison of Toxoplasma gondii Seroprevalence in Shelter Cats and Dogs during 1999-2001 and 2009-2011 in Tokyo,

818 Oro D., Genovart M., Tavecchia G., Fowler MS., Martínez-Abraín A. 2013. Ecological and evolutionary implications of food subsidies from humans. Ecology Letters 16:1501-1514.

820 DOI: $10.1111 /$ ele. 12187.

821

Parr NA., Fedigan LM., Kutz SJ. 2013. Predictors of Parasitism in Wild White-Faced Capuchins (Cebus capucinus). International Journal of Primatology 34:1137-1152. DOI:

823 10.1007/s10764-013-9728-2.

824 Peterson MN., Hartis B., Rodriguez S., Green M., Lepczyk CA. 2012. Opinions from the Front 825 Lines of Cat Colony Management Conflict. PLOS ONE 7:e44616. DOI:

826 10.1371/journal.pone.0044616.

827 Plummer KE., Bearhop S., Leech DI., Chamberlain DE., Blount JD. 2013. Winter food 828 provisioning reduces future breeding performance in a wild bird. Scientific Reports

829 $3: 2002$.

Pontier D., Fouchet D., Bahi-Jaber N., Poulet H., Guiserix M., Natoli E., Sauvage F. 2009. When 831 domestic cat (Felis silvestris catus) population structures interact with their viruses. Comptes rendus biologies 332:321-328. DOI: 10.1016/j.crvi.2008.07.012.

833 Pontier D., Natoli E. 1996. Male reproductive success in the domestic cat (Felis catus L.): A case 834 history. Behavioural Processes 37:85-88. DOI: 10.1016/0376-6357(95)00070-4. 
835 PUTMAN RJ., STAINES BW. 2004. Supplementary winter feeding of wild red deer Cervus 836 elaphus in Europe and North America: justifications, feeding practice and effectiveness.

838 Radford AD., Addie D., Belak S., Boucraut-Baralon C., Egberink H., Frymus T., Gruffydd-Jones T., Hartmann K., Hosie MJ., Lloret A., Lutz H., Marsilio F., Pennisi MG., Thiry E., Truyen U., Horzinek MC. 2009. Feline calicivirus infection. ABCD guidelines on prevention and management. Journal of feline medicine and surgery 11:556-564. DOI: 10.1016/j.jfms.2009.05.004.

Radford AD., Coyne KP., Dawson S., Porter CJ., Gaskell RM. 2007. Feline calicivirus. Vet. Res. $38: 319-335$.

Ravi M., Wobeser GA., Taylor SM., Jackson ML. 2010. Naturally acquired feline immunodeficiency virus (FIV) infection in cats from western Canada: Prevalence, disease associations, and survival analysis. The Canadian Veterinary Journal 51:271276.

Rickett J., Dey CJ., Stothart J., O'Connor CM., Quinn JS., Ji W. 2013. The influence of supplemental feeding on survival, dispersal and competition in translocated Brown Teal,

853 Robb GN., McDonald RA., Chamberlain DE., Bearhop S. 2008. Food for thought: supplementary feeding as a driver of ecological change in avian populations. Frontiers in 855 Ecology and the Environment 6:476-484. DOI: 10.1890/060152. 
856 Rodriguez-Hidalgo P., Gortazar C., Tortosa FS., Rodriguez-Vigal C., Fierro Y., Vicente J. 2010. 857 Effects of density, climate, and supplementary forage on body mass and pregnancy rates 858 of female red deer in Spain. Oecologia 164:389-398. DOI: 10.1007/s00442-010-1663-8.

859 Rojko JL., Olsen RG. 1984. The immunobiology of the feline leukemia virus. Veterinary $860 \quad$ immunology and immunopathology 6:107-165.

861 Scott KC., Levy JK., Gorman SP., Newell SM. 2002. Body condition of feral cats and the effect 862 of neutering. Journal of applied animal welfare science: JAAWS 5:203-213. DOI:

863

864

865

Seber GAF. 1992. A Review of Estimating Animal Abundance II. International Statistical 10.1207/S15327604JAWS0503_04.

866

867

868

869

870

871

872

873

874

875

876

877

$$
\text { Review / Revue Internationale de Statistique 60:129-166. DOI: 10.2307/1403646. }
$$

Semeniuk CAD, Rothley KD 2008. Costs of group-living for a normally solitary forager: effects of provisioning tourism on southern stingrays Dasyatis americana. Marine Ecology Progress Series 357:271-282.

Spada E., Proverbio D., Galluzzo P., Della Pepa A., Perego R., Bagnagatti De Giorgi G., Ferro E. 2014. Molecular study on selected vector-borne infections in urban stray colony cats in northern Italy. Journal of feline medicine and surgery 16:684-688. DOI: $10.1177 / 1098612 X 13514422$.

Stojanovic V., Foley P. 2011. Infectious disease prevalence in a feral cat population on Prince Edward Island, Canada. Canadian Veterinary Journal 52:979-982.

Tennent J., Downs CT. 2008. Abundance and home ranges of feral cats in an urban conservancy where there is supplemental feeding: a case study from South Africa. African Zoology 43:218-229. DOI: 10.3377/1562-7020-43.2.218. 
878 Thiry E., Addie D., Belak S., Boucraut-Baralon C., Egberink H., Frymus T., Gruffydd-Jones T., 879 Hartmann K., Hosie MJ., Lloret A., Lutz H., Marsilio F., Pennisi MG., Radford AD., 880 Truyen U., Horzinek MC. 2009. Feline herpesvirus infection. ABCD guidelines on 881 882 prevention and management. Journal of feline medicine and surgery 11:547-555. DOI:

\section{3}

884

885 886 887 888 889

890 10.1016/j.jfms.2009.05.003.

Thrall PH., Antonovics J., Hall DW. 1993. Host and Pathogen Coexistence in Sexually Transmitted and Vector-Borne Diseases Characterized by Frequency-Dependent Disease Transmission. The American Naturalist:543.

Truyen U., Addie D., Belak S., Boucraut-Baralon C., Egberink H., Frymus T., Gruffydd-Jones T., Hartmann K., Hosie MJ., Lloret A., Lutz H., Marsilio F., Pennisi MG., Radford AD., Thiry E., Horzinek MC. 2009. Feline panleukopenia. ABCD guidelines on prevention and management. Journal of feline medicine and surgery 11:538-546. DOI:

891 892 893 10.1016/j.jfms.2009.05.002.

Vicente J., Hofle U., Fernandez-De-Mera IG., Gortazar C. 2007. The importance of parasite life history and host density in predicting the impact of infections in red deer. Oecologia 152:655-664. DOI: 10.1007/s00442-007-0690-6.

894 Walker Vergara R., Morera Galleguillos F., Gómez Jaramillo M., Pereira Almosny NR., Arauna 895 Martínez P., Grob Behne P., Acosta-Jamett G., Müller A. 2016. Prevalence, risk factor 896 analysis, and hematological findings of hemoplasma infection in domestic cats from Valdivia, Southern Chile. Comparative Immunology, Microbiology and Infectious Diseases 46:20-26. DOI: 10.1016/j.cimid.2016.03.004. 
899 Wang Q., Jiang W., Chen Y-J., Liu C-Y., Shi J., Li X. 2012. Prevalence of Toxoplasma gondii 900 antibodies, circulating antigens and DNA in stray cats in Shanghai, China. Parasites \& 901 vectors 5:190. DOI: $10.1186 / 1756-3305-5-190$.

902 Willi B., Boretti FS., Tasker S., Meli ML., Wengi N., Reusch CE., Lutz H., Hofmann-Lehmann 903 R. 2007. From Haemobartonella to hemoplasma: Molecular methods provide new 904 insights. Veterinary Microbiology 125:197-209. DOI: 10.1016/j.vetmic.2007.06.027.

905 Wright AN., Gompper ME. 2005. Altered parasite assemblages in raccoons in response to 906 manipulated resource availability. Oecologia 144:148-156. DOI: 10.1007/s00442-005$907 \quad 0018-3$.

908 Yamaguchi N., Macdonald DW., Passanisi WC., Harbour DA., Hopper CD. 1996. Parasite 909 prevalence in free-ranging farm cats, Felis silvestris catus. Epidemiology and infection 910 116:217-223.

911

912 
913 S1 Figure. Typical landscape of residential area of Seoul where the density survey was $914 \quad$ performed

915

916 
Figure 1

CCA (PC1) in the districts of Seoul based on the PCA result

The six districts selected are; GN, SC and MP on the upper right side (high CCA districts;

yellow), and GC, DDM and SD on the lower left side (lower CCA districts; blue). District SP and GD was excluded from the study site due to logistical reasons.

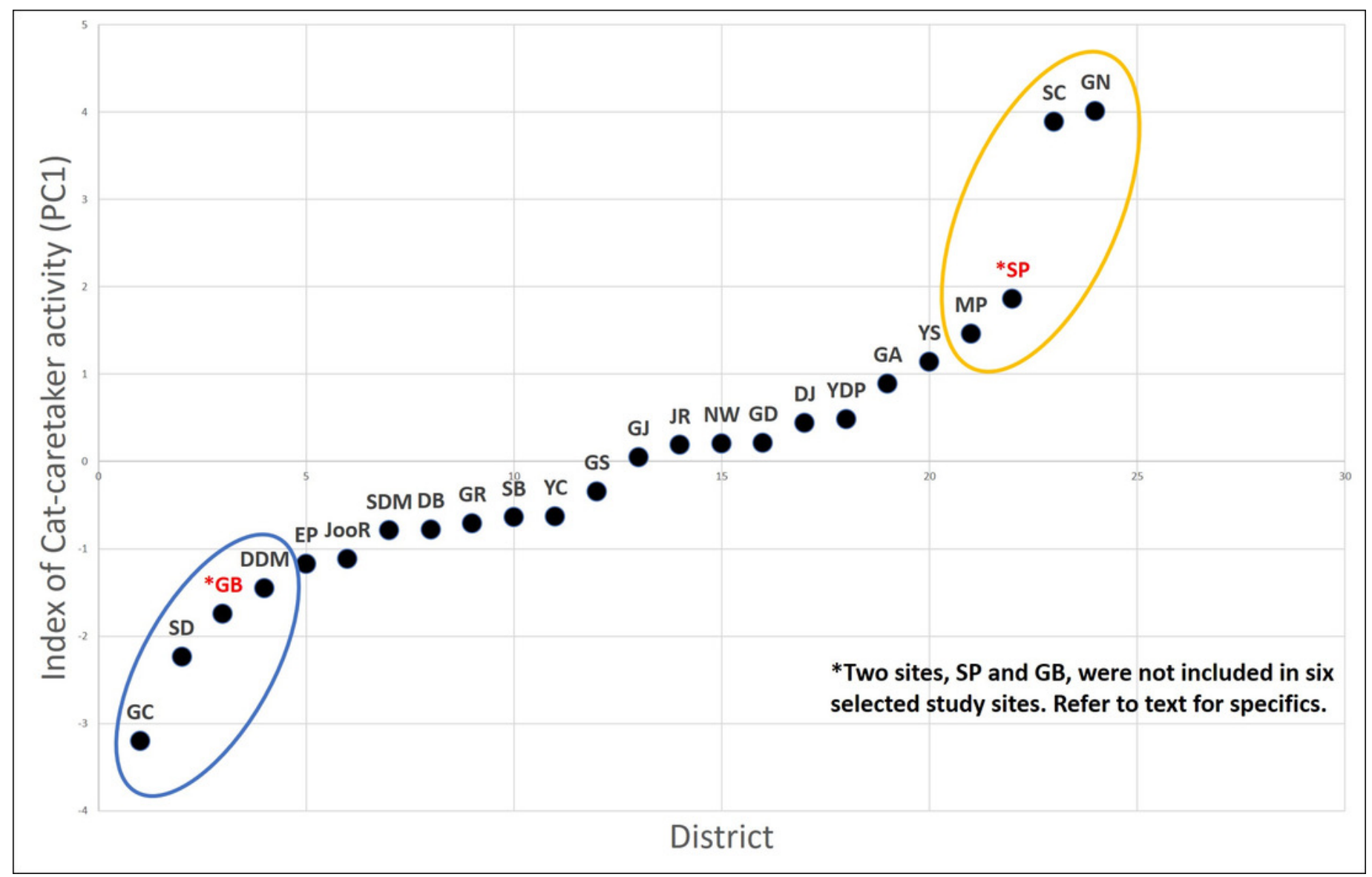


Figure 2

Map of Seoul showing the 6 districts where the study was performed

High CCA districts in red letters and low CCA districts in blue letters.

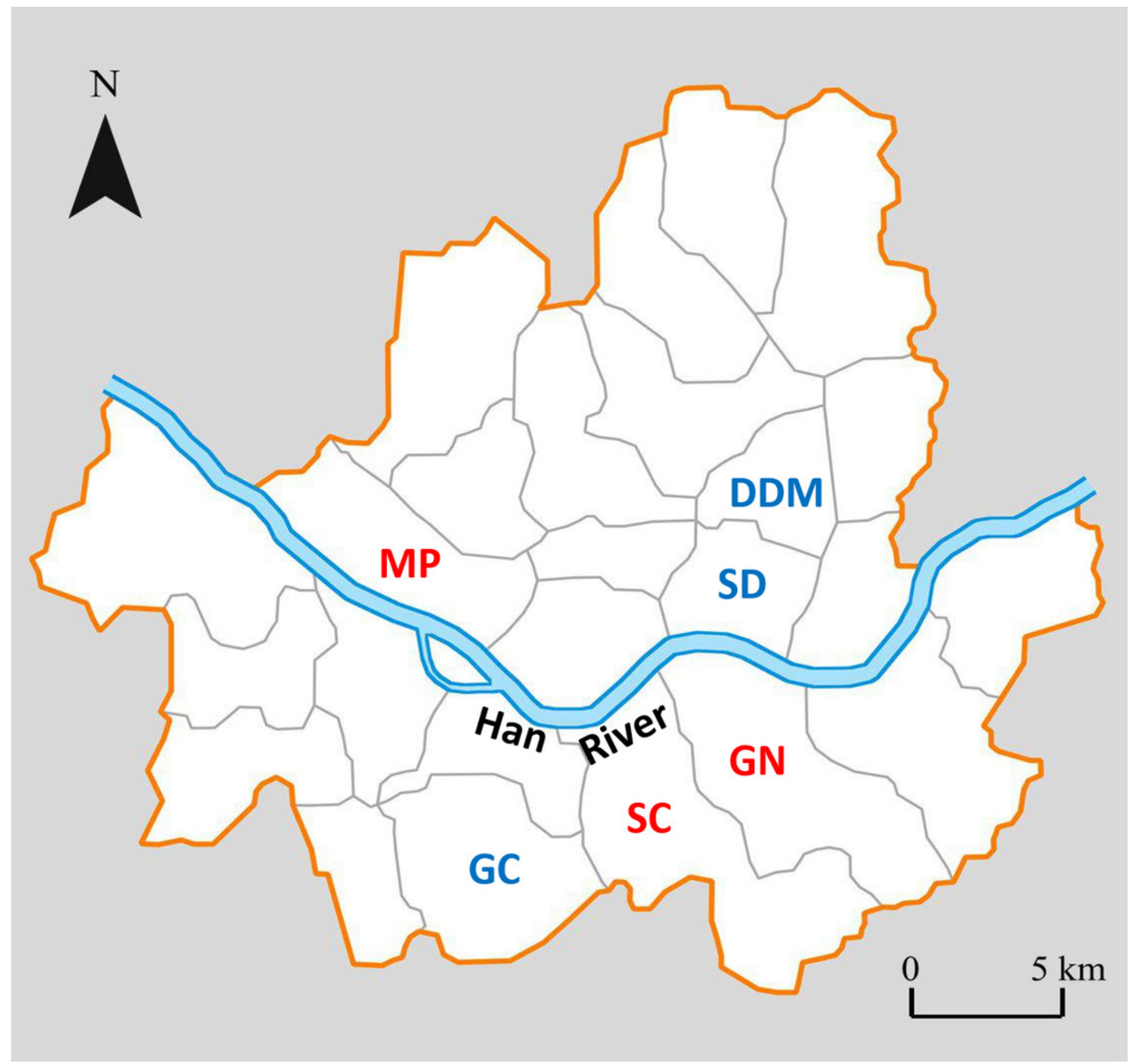




\section{Figure 3}

Cat population density estimates (95\% confidence intervals) from the 12 survey sites

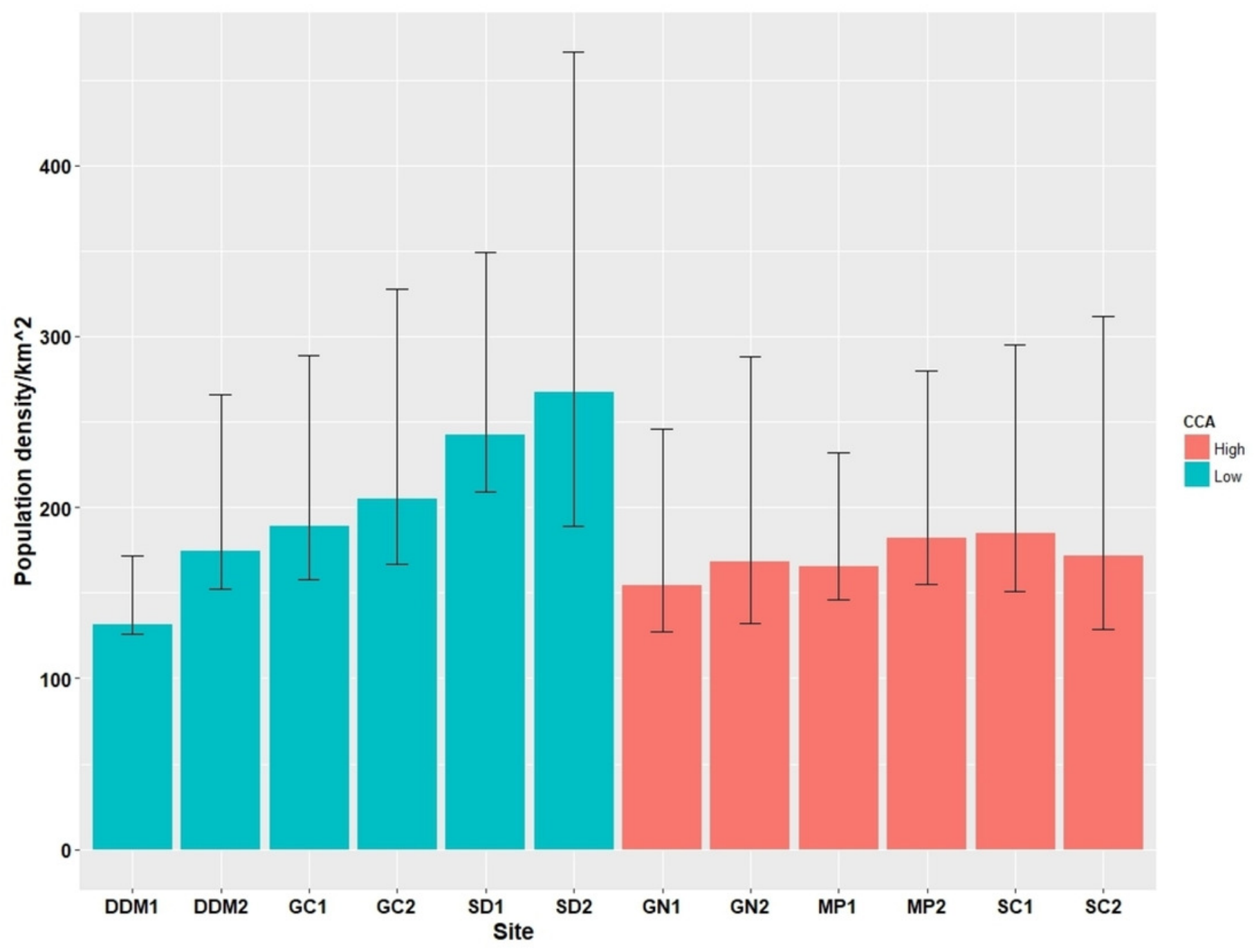




\section{Table $\mathbf{1}$ (on next page)}

Transmission modes of studied pathogens.

Specific transmission routes of studied pathogens and its relative position along the continuum between density-dependent and frequency-dependent transmission 


\begin{tabular}{|c|c|c|}
\hline Pathogens & Transmission modes & $\begin{array}{c}\text { Relative position of } \\
\text { pathogens on continuum of } \\
\text { transmission modes }\end{array}$ \\
\hline $\begin{array}{l}\text { Feline Calicivirus } \\
\text { (FCV) }\end{array}$ & $\begin{array}{c}\text { Aerosol in close } \\
\text { proximity, direct contact } \\
\text { with contaminated } \\
\text { objects or infected cats }\end{array}$ & \multirow{8}{*}{$\begin{array}{l}\text { Density-dependent } \\
\text { transmission } \\
\text { Frequency-dependent } \\
\text { transmission }\end{array}$} \\
\hline $\begin{array}{c}\text { Feline Herpesvirus } \\
\text { (FHV) }\end{array}$ & $\begin{array}{c}\text { Aerosol in close } \\
\text { proximity, direct contact } \\
\text { with contaminated } \\
\text { objects or infected cats }\end{array}$ & \\
\hline $\begin{array}{c}\text { Feline leukemia } \\
\text { virus (FeLV) }\end{array}$ & $\begin{array}{c}\text { Saliva, aerosol in close } \\
\text { proximity }\end{array}$ & \\
\hline Toxoplasma gonii & $\begin{array}{l}\text { Prey consumption } \\
\text { contact with } \\
\text { contaminated abiotic } \\
\text { materials (e.g. feces) }\end{array}$ & \\
\hline $\begin{array}{c}\text { Feline Parvovirus } \\
(\mathrm{FPV})\end{array}$ & $\begin{array}{c}\text { Saliva, blood, urine and } \\
\text { feces }\end{array}$ & \\
\hline Bartonella henselae & Vector-borne, mostly flea & \\
\hline Hemoplasma & $\begin{array}{c}\text { Through saliva and/or } \\
\text { arthropod vectors }\end{array}$ & \\
\hline $\begin{array}{c}\text { Feline } \\
\text { Immunodeficiency } \\
\text { Virus (FIV) }\end{array}$ & $\begin{array}{l}\text { Aggressive behavior } \\
\text { during breeding seasons- } \\
\text { saliva and bite wounds }\end{array}$ & \\
\hline
\end{tabular}

1 


\section{Table 2 (on next page)}

Principal components (PC1 and PC2) eigenvalues and PC loadings for the CCA parameters 


\begin{tabular}{|c|c|c|}
\hline & PC1 & PC2 \\
\hline Eigenvalue & 3.12 & 1.41 \\
\hline Percentage variation explained & 0.39 & 0.18 \\
\hline \multicolumn{3}{|l|}{ Eigenvectors } \\
\hline Matriculation rate & 0.45 & -0.27 \\
\hline Property tax & 0.46 & -0.11 \\
\hline Proportion of survey respondents & 0.37 & -0.42 \\
\hline $\begin{array}{l}\text { Proportion of respondents taking care } \\
\text { of more than ten cats }\end{array}$ & 0.24 & 0.58 \\
\hline $\begin{array}{l}\text { Proportion of cat caretakers with } \\
\text { more than five years of experience }\end{array}$ & 0.29 & 0.39 \\
\hline $\begin{array}{l}\text { Provide food supplement daily in a } \\
\text { regular manner }\end{array}$ & 0.27 & 0.41 \\
\hline $\begin{array}{l}\text { Provide food in areas further than a } \\
100 \text {-meter radius from their house }\end{array}$ & 0.25 & -0.27 \\
\hline $\begin{array}{l}\text { Subjective score about the intensity } \\
\text { of the CCA in his/her residing district }\end{array}$ & 0.42 & 0.08 \\
\hline
\end{tabular}


Table 3(on next page)

Estimated population densities (95\% confidence intervals) and proportion of observed cats with the sterilization mark from the six districts (CCA indicated in parenthesis; high$\mathrm{H}$, low-L) 


\begin{tabular}{|c|c|c|c|c|}
\hline $\begin{array}{l}\text { District } \\
\text { (CCA) }\end{array}$ & $\begin{array}{l}\text { Site } \\
\text { ID }\end{array}$ & $\begin{array}{l}\text { Area } \\
\left(\mathbf{k m}^{2}\right)\end{array}$ & $\begin{array}{l}\text { Estimated cat density } \\
\left(95 \% \text { CI cats per } \mathrm{km}^{2}\right)\end{array}$ & $\begin{array}{l}\text { Proportion of } \\
\text { sterilized cats* }\end{array}$ \\
\hline \multirow{2}{*}{ GN (H) } & GN1 & 0.14 & $155(127-246)$ & 0.24 \\
\hline & GN2 & 0.17 & $168(132-288)$ & 0.68 \\
\hline \multirow{2}{*}{$\mathrm{SC}(\mathrm{H})$} & $\mathrm{SC1}$ & 0.19 & $185(151-295)$ & 0.30 \\
\hline & $\mathrm{SC} 2$ & 0.17 & $172(129-312)$ & 0.22 \\
\hline \multirow{2}{*}{$\mathrm{MP}(\mathrm{H})$} & MP1 & 0.15 & $166(146-232)$ & 0.14 \\
\hline & MP2 & 0.18 & $182(155-280)$ & 0.58 \\
\hline \multirow{2}{*}{ DDM (L) } & DDM1 & 0.18 & $132(126-172)$ & 0.19 \\
\hline & DDM2 & 0.13 & $175(152-266)$ & 0.00 \\
\hline \multirow{2}{*}{$\mathrm{GC}(\mathrm{L})$} & GC1 & 0.19 & $189(158-289)$ & 0.22 \\
\hline & GC2 & 0.16 & $206(167-328)$ & 0.08 \\
\hline \multirow{2}{*}{$\mathrm{SD}(\mathrm{L})$} & SD1 & 0.18 & $243(209-349)$ & 0.00 \\
\hline & SD2 & 0.21 & $268(189-466)$ & 0.10 \\
\hline
\end{tabular}

1 * Calculated as 'number of observed cats with an ear mark/ number of total observed cats'. 


\section{Table 4 (on next page)}

Prevalence (\%), 95\% confidence interval and sample size (n)) of each pathogen from the stray cats in the six studied districts (Letter inside the parentheses indicates the CCA of each district; H-high, L-low) 
Prevalence (\%), 95\% confidence interval and sample size (n)) of each pathogen

\begin{tabular}{|c|c|c|c|c|c|c|c|c|}
\hline \multirow{2}{*}{ District } & \multicolumn{8}{|c|}{ Prevalence $(\%), 95 \%$ confidence interval and sample size $(n))$ of each pathogen } \\
\hline & FIV & $\begin{array}{l}\text { Feline } \\
\text { Hemoplasma }\end{array}$ & B. henselae & T. gondii & FPV & FeLV & FCV & FHV-1 \\
\hline \multirow{3}{*}{ GN (H) } & $0 \%$ & $26.0 \%$ & $42.0 \%$ & $6.0 \%$ & $59.0 \%$ & $42.0 \%$ & $100 \%$ & $100 \%$ \\
\hline & (0.00-0.05, & (0.15-0.39, & (0.29-0.56, & $(0.02-0.15$, & (0.45-0.72, & $(0.28-0.56$ & $(0.95-1.00$ & (0.95-1.00, \\
\hline & $\mathrm{n}=50)$ & $\mathrm{n}=50)$ & $\mathrm{n}=50))$ & $\mathrm{n}=50)$ & $\mathrm{n}=49)$ & $\mathrm{n}=50)$ & $\mathrm{n}=50)$ & $\mathrm{n}=50)$ \\
\hline \multirow{3}{*}{$\mathrm{SC}(\mathbf{H})$} & $6.0 \%$ & $38.0 \%$ & $30.0 \%$ & $6.0 \%$ & $76.0 \%$ & $36.0 \%$ & $92.0 \%$ & $94.0 \%$ \\
\hline & $(0.02-0.15$ & $(0.26-0.52$ & $(0.19-0.44$ & $(0.02-0.15$, & (0.63-0.86, & $(0.24-0.50$ & $(0.82-0.97$ & $(0.85-0.98$, \\
\hline & $\mathrm{n}=50)$ & $\mathrm{n}=50)$ & $\mathrm{n}=50)$ & $\mathrm{n}=50)$ & $\mathrm{n}=50)$ & $\mathrm{n}=50)$ & $\mathrm{n}=50)$ & $\mathrm{n}=50)$ \\
\hline \multirow{3}{*}{ MP (H) } & $6.0 \%$ & $48.0 \%$ & $42.0 \%$ & $6.3 \%$ & $75.5 \%$ & $12.0 \%$ & $98.0 \%$ & $96.0 \%$ \\
\hline & $(0.02-0.15$ & $0.35-0.62$ & (0.29-0.56, & (0.02-0.16, & (0.64-0.87, & (0.03-0.21, & (0.91-1.00, & (0.88-0.99, \\
\hline & $\mathrm{n}=50)$ & $\mathrm{n}=50)$ & $\mathrm{n}=50)$ & $\mathrm{n}=48)$ & $\mathrm{n}=49)$ & $\mathrm{n}=50)$ & $\mathrm{n}=49)$ & $\mathrm{n}=49)$ \\
\hline
\end{tabular}




\begin{tabular}{|c|c|c|c|c|c|c|c|c|}
\hline \multirow{3}{*}{ DDM (L) } & $4.0 \%$ & $28.0 \%$ & $32.0 \%$ & $4.0 \%$ & $94.0 \%$ & $20.0 \%$ & $100 \%$ & $100 \%$ \\
\hline & $(0.01-0.12$ & (0.17-0.41, & $(0.20-0.46$ & $(0.01-0.12$ & (0.85-0.98, & (0.11-0.33, & (0.95-1.00, & (0.95-1.00, \\
\hline & $\mathrm{n}=50)$ & $\mathrm{n}=50)$ & $\mathrm{n}=50)$ & $\mathrm{n}=50)$ & $\mathrm{n}=50)$ & $\mathrm{n}=50)$ & $\mathrm{n}=50)$ & $\mathrm{n}=50)$ \\
\hline \multirow{3}{*}{ GC (L) } & $4.0 \%$ & $28.0 \%$ & $34.0 \%$ & $12.0 \%$ & $80.0 \%$ & $14.0 \%$ & $92.0 \%$ & $100 \%$ \\
\hline & $(0.01-0.12$ & $(0.17-0.41$, & $(0.22-0.48$ & (0.05-0.23, & (0.67-0.89, & $(0.07-0.26$ & (0.82-0.97, & (0.95-1.00, \\
\hline & $\mathrm{n}=50)$ & $\mathrm{n}=50)$ & $\mathrm{n}=50)$ & $\mathrm{n}=50)$ & $\mathrm{n}=50)$ & $\mathrm{n}=50)$ & $\mathrm{n}=50)$ & $\mathrm{n}=50)$ \\
\hline \multirow{3}{*}{ SD (L) } & $1.9 \%$ & $26.9 \%$ & $28.8 \%$ & $12.0 \%$ & $90.0 \%$ & $15.4 \%$ & $86.0 \%$ & $100 \%$ \\
\hline & (0.00-0.09, & $(0.16-0.5$ & $(0.18-0.42$, & (0.05-0.23, & $(0.80-0.96$ & (0.08-0.27, & $(0.75-0.94$ & (0.95-1.00, \\
\hline & $\mathrm{n}=52)$ & $\mathrm{n}=52)$ & $\mathrm{n}=52)$ & $\mathrm{n}=50)$ & $\mathrm{n}=50)$ & $\mathrm{n}=52)$ & $\mathrm{n}=50)$ & $\mathrm{n}=50)$ \\
\hline
\end{tabular}




\section{Table 5 (on next page)}

AICC values and AICc weights of the most parsimonious candidate models (models within 2 units of the $\triangle \mathrm{AICc}$ ) testing the effect of the explanatory variables (sex, population density ( $\mathrm{pd}$ ) and $\mathrm{CCA}$ ) on the prevalence of the eight studied pathogens. 


\begin{tabular}{|c|c|c|c|c|c|}
\hline Pathogen & Model* & $\mathbf{K}$ & AICc & $\triangle \mathrm{AICc}$ & $\begin{array}{l}\text { AICc } \\
\text { weight }\end{array}$ \\
\hline \multirow{2}{*}{ FeLV } & $\operatorname{sex}+\mathrm{CCA}$ & 4 & 318.97 & 0.00 & 0.62 \\
\hline & $\mathrm{sex}+\mathrm{pd}+\mathrm{CCA}$ & 5 & 320.80 & 1.84 & 0.25 \\
\hline \multirow{2}{*}{ FPV } & $\mathrm{CCA}$ & 3 & 294.25 & 0.00 & 0.39 \\
\hline & $\mathrm{sex}+\mathrm{CCA}$ & 4 & 294.57 & 0.31 & 0.34 \\
\hline \multirow{3}{*}{ Hemoplasma } & $\mathbf{s e x}+\mathrm{CCA}$ & 4 & 375.39 & 0.00 & 0.35 \\
\hline & & 3 & 375.50 & 0.12 & 0.33 \\
\hline & sex + pd & 4 & 376.86 & 1.48 & 0.17 \\
\hline \multirow{3}{*}{$\begin{array}{l}\text { Toxoplasma } \\
\text { gondii }\end{array}$} & $\operatorname{sex}+p d$ & 4 & 159.77 & 0.00 & 0.34 \\
\hline & sex & 3 & 160.29 & 0.52 & 0.26 \\
\hline & $\operatorname{sex}+\mathrm{CCA}$ & 4 & 161.64 & 1.87 & 0.13 \\
\hline \multirow{3}{*}{$\mathrm{FCV}$} & pd & 3 & 117.76 & 0.00 & 0.38 \\
\hline & $\mathrm{pd}+\mathrm{sex}$ & 4 & 118.19 & 0.43 & 0.31 \\
\hline & $\mathrm{pd}+\mathrm{CCA}$ & 4 & 119.47 & 1.71 & 0.16 \\
\hline \multirow{4}{*}{ FHV-1 } & $\mathbf{p d}+\mathrm{CCA}$ & 4 & 47.73 & 0.00 & 0.27 \\
\hline & $\mathrm{CCA}$ & 3 & 47.81 & 0.09 & 0.25 \\
\hline & $s e x+p d+C C A$ & 5 & 48.16 & 0.43 & 0.21 \\
\hline & $\mathrm{sex}+\mathrm{CCA}$ & 4 & 48.30 & 0.57 & 0.20 \\
\hline \multirow{4}{*}{ FIV } & Null & 2 & 96.56 & 0.00 & 0.37 \\
\hline & $\mathrm{pd}$ & 3 & 98.34 & 1.78 & 0.15 \\
\hline & $\mathrm{CCA}$ & 3 & 98.48 & 1.93 & 0.14 \\
\hline & sex & 3 & 98.52 & 1.96 & 0.14 \\
\hline \multirow{4}{*}{$\begin{array}{l}\text { Bartonella } \\
\text { henselae }\end{array}$} & Null & 2 & 392.20 & 0.00 & 0.25 \\
\hline & CCA & 3 & 392.85 & 0.65 & 0.18 \\
\hline & $\mathrm{pd}$ & 3 & 392.98 & 0.78 & 0.17 \\
\hline & sex & 3 & 393.87 & 1.67 & 0.11 \\
\hline
\end{tabular}

1 *Abbreviated model variables: $\mathrm{pd}=$ population density, $\mathrm{CCA}=$ cat caretaker activity 


\section{Table 6(on next page)}

Model-averaged parameter estimates included in the most parsimonious models (models within 2 units of the $\triangle \mathrm{AICC}$ ) for each pathogen 


\begin{tabular}{|c|c|c|c|c|c|c|}
\hline & Coefficient & S.E. & $\begin{array}{l}\text { Upper } \\
\text { CI }\end{array}$ & $\begin{array}{l}\text { Lower } \\
\text { CI }\end{array}$ & $\begin{array}{l}\text { Odds } \\
\text { ratio }\end{array}$ & P-value \\
\hline \multicolumn{7}{|l|}{ FeLV } \\
\hline CCA; low & -0.81 & 0.30 & -1.42 & -0.20 & 0.44 & $<0.01$ \\
\hline sex; male & -0.74 & 0.29 & -1.32 & -0.17 & 0.48 & 0.01 \\
\hline $\mathrm{pd}$ & -0.00 & 0.01 & -0.02 & 0.01 & 0.99 & 0.41 \\
\hline \multicolumn{7}{|l|}{ FPV } \\
\hline CCA; low & 1.12 & 0.31 & 0.52 & 1.74 & 3.08 & $<0.01$ \\
\hline sex; male & -0.35 & 0.30 & -0.93 & 0.23 & 0.70 & 0.24 \\
\hline \multicolumn{7}{|c|}{ hemoplasma } \\
\hline CCA; low & -0.37 & 0.25 & -0.91 & 0.07 & 0.66 & 0.15 \\
\hline sex; male & 0.79 & 0.26 & 0.30 & 1.30 & 2.23 & $<0.01$ \\
\hline $\mathrm{pd}$ & -0.00 & 0.00 & -0.01 & 0.01 & 0.99 & 0.67 \\
\hline \multicolumn{7}{|c|}{ Toxoplasma } \\
\hline \multicolumn{7}{|c|}{ gondii } \\
\hline CCA; low & 0.38 & 0.45 & -0.50 & 1.27 & 1.47 & 0.40 \\
\hline sex; male & -1.11 & 0.49 & -2.07 & -0.14 & 0.33 & 0.03 \\
\hline $\mathrm{pd}$ & 0.01 & 0.01 & -0.00 & 0.02 & 1.01 & 0.08 \\
\hline \multicolumn{7}{|l|}{ FCV } \\
\hline CCA; low & 0.38 & 0.82 & -1.28 & 1.99 & 1.47 & 0.64 \\
\hline sex; male & -0.63 & 0.55 & -1.70 & 0.45 & 0.54 & 0.25 \\
\hline pd & -0.02 & 0.01 & -0.04 & -0.01 & 0.98 & $<0.01$ \\
\hline \multicolumn{7}{|l|}{ FHV-1 } \\
\hline CCA; low & 27.53 & 2701.87 & -5268.04 & 5323.11 & $9.08 \times 10^{\wedge 11}$ & 0.99 \\
\hline sex; male & -1.25 & 1.14 & -3.49 & 0.99 & 0.29 & 0.28 \\
\hline $\mathrm{Pd}$ & -0.18 & 0.13 & -0.43 & 0.07 & 0.84 & 0.16 \\
\hline \multicolumn{7}{|l|}{ FIV } \\
\hline CCA; low & -0.14 & 0.65 & -1.28 & 1.25 & 0.99 & 0.98 \\
\hline sex; male & 0.14 & 0.65 & -1.25 & 1.28 & 1.01 & 0.98 \\
\hline $\mathrm{Pd}$ & -0.00 & 0.01 & -0.02 & 0.02 & 1.00 & 0.82 \\
\hline \multicolumn{7}{|l|}{ Bartonella } \\
\hline \multicolumn{7}{|l|}{ henselae } \\
\hline CCA; low & -0.29 & 0.25 & -0.77 & 0.19 & 0.75 & 0.24 \\
\hline sex; male & -0.19 & 0.25 & -0.67 & 0.29 & 0.83 & 0.44 \\
\hline $\mathrm{Pd}$ & -0.00 & 0.00 & -0.01 & 0.00 & 1.00 & 0.35 \\
\hline
\end{tabular}

